Absolute stereochemistry of fungal beauveriolide III and ACAT inhibitory activity of four stereoisomers.

Taichi Ohshiro, $^{\dagger}$ Ichiji Namatame,$^{\dagger}$ Kenichiro Nagai, ${ }^{\dagger}$ Takafumi Sekiguchi, ${ }^{\ddagger}$ Takayuki Doi, ${ }^{\ddagger}$

Takashi Takahashi, ${ }^{\star}$ Kazuaki Akasaka, 'Lawrence L. Rudel ${ }^{\S}$, Hiroshi Tomoda, ${ }^{\#, \perp, *}$ and Satoshi $\overline{\mathrm{O}}$ mura, ${ }^{\dagger, \perp}$

$\uparrow$ Kitasato Institute for Life Sciences and Graduate School of Infection Control Sciences, Kitasato University, 5-9-1 Shirokane, Minato-ku, Tokyo 108-8641, Japan, $\ddagger$ Department of Applied Chemistry, Tokyo Institute of Technology, 2-12-1 Ookayama, Meguro-ku, Tokyo 152-8552, Japan, • Graduate School of Life Sciences, Tohoku University, 1-1 Tsutsumidori-Amamiyamachi, Aobaku, Sendai 9818555, Japan, $\perp$ The Kitasato Institute, 5-9-1 Shirokane, Minato-ku, Tokyo 108-8642, Japan, $§$ Department of Pathology, Atherosclerosis Research Program, Wake Forest University School of Medicine, Winston-Salem, NC, USA, \# School of Pharmacy, Kitasato University , 5-9-1 Shirokane, Minato-ku, Tokyo 108-8641, Japan

tomodah@pharm.kitasato-u.ac.jp

General experimental details and synthetic procedures S2-S16

Comparison optical rotation of 5, 10, ent-5 and ent-10 (Table S1) S17

${ }^{1} \mathrm{H}$ NMR spectral for compounds $\quad$ S18-S28

$\begin{array}{ll}\text { Biological assay procedures } & \text { S29 }\end{array}$ 
NMR spectra were recorded on a JEOL JNM-EX270 instrument with $\mathrm{CDCl}_{3} \cdot{ }^{1} \mathrm{H}$ NMR (270 MHz) spectral data are reported as follows: chemical shifts relative chloroform (7.26 ppm), Multiplicity ( $\mathrm{s}=$ singlet, $\mathrm{d}=$ doublet, $\mathrm{t}=$ triplet, $\mathrm{q}=$ quartet, $\mathrm{m}=$ =multiplet, brbroad), coupling and integration. ${ }^{13} \mathrm{C}$ NMR (67.9 MHz) spectal data are reported in ppm relative to CDCl3 (77.0 ppm). Melting points were measured with Yanaco micromelting point apparatus. FT-IR specta were recorded a Horiba FT-210 spectrometer. Optical rotation was obtained with a JASCO DIP-370 polarimeter. HRFABMS were measured with a JEOL JMS-AX505 HA mass spectrometer.

Materials. Reagents and solvents were purchased from commercial sources and used without further purification.

\section{Synthesis of Four HMA stereoisomers.}

\section{Ethyl (3S,4S)-3-hydroxy-4-methyloctanoate (3)}

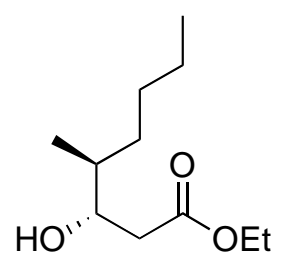

$\mathrm{RuCl}_{2}(\mathrm{R})$-BINAP (81.0 mg, $0.103 \mathrm{mmol}$ ) was placed in a glass vessel under nitrogen, then a solution of ethyl (S)-3-oxo-4-methyloctanoate (2)(2.08 g, $10.3 \mu \mathrm{mol})$ in degassed ethanol (15 mL) was added to this vessel, and placed in $50 \mathrm{~mL}$ stainless steel autoclave. Hydrogen was pressurized to $90 \mathrm{~atm}$ and the mixture was stirred at $45^{\circ} \mathrm{C}$ for $40 \mathrm{~h}$. The solvent was removed in reduced pressure. The crude was filtered through florizil. The filtrate was purified by column chromatography on silica gel (100 mL, hexane:ethyl acetate $=10: 1)$ to provide ethyl $(3 S, 4 S)$-3-hydroxy-4-methyloctanoate $(3)(2.05$ g, $98 \%)$ as 
a colorless oil.; $[\alpha]_{\mathrm{D}}{ }^{24}=-35$ (c 1.01, $\mathrm{CHCl}_{3}$ ); HRFABMS : calcd for $\mathrm{C}_{11} \mathrm{H}_{23} \mathrm{O}_{3}[\mathrm{M}+\mathrm{H}]^{+}$: 203.1647, found: 203.1649; IR (neat) : 3475, 2958, 2929, 2859, 1731, 1465, 1375, 1278, 1182, $1133 \mathrm{~cm}^{-1} ;{ }^{1} \mathrm{H}$ NMR (270 MHz, $\left.\mathrm{CDCl}_{3}\right) \delta(\mathrm{ppm}): 4.18$ (q, $\left.j=7.3 \mathrm{~Hz}, 2 \mathrm{H}\right), 3.92$ (m, 1H), 2.74 (brs, 1H), 2.49 (d, $j=$ 16.2 Hz, 1H), 2.36 (d, $j=16.2 \mathrm{~Hz}, 1 \mathrm{H}), 1.61-1.41(\mathrm{~m}, 2 \mathrm{H}), 1.30-1.11(\mathrm{~m}, 8 \mathrm{H}), 0.91(\mathrm{~d}, j=6.9 \mathrm{~Hz}, 3 \mathrm{H})$, $0.89(\mathrm{t}, j=6.9 \mathrm{~Hz}, 3 \mathrm{H}) ;{ }^{13} \mathrm{C}$ NMR (67.9 $\left.\mathrm{MHz} \mathrm{CDCl}_{3}\right) \delta(\mathrm{ppm})$ : 14.1, 14.2, 14.3, 23.0, 29.6, 32.5, 38.1, 38.9, 60.7, 71.3, 173.6 .

\section{(3S,4S)-3-hydroxy-4-methyloctanic acid (4) and Benzyl (3S,4S)-3-hydroxy-4-methyloctanoate}

To a solution of 3 (2.05 g, $10.1 \mathrm{mmol})$ in THF (45 mL) and methanol (5 mL) was added 1M lithium hydroxide (20 mL, $41.2 \mathrm{mmol}$ ) and this mixture was stirred at room temperature. After stirring for $2.5 \mathrm{~h}$, methanol was removed in reduced pressure. The mixture was quenched with 1M hydrogen chloride (15 $\mathrm{mL}$ ) and extracted with ethyl acetate (50 mL x 3). The combined organic layer was washed with brine (100 mL), dried over $\mathrm{MgSO}_{4}$, filtered and evaporated in vacuo to give crude (3S,4S)-3-hydroxy-4methyloctanic acid (4) which was used for the next reaction without further purification. To an icecooled solution of the crude product in methanol $(2 \mathrm{~mL})$ was added a solution of cesium carbonate (1.80 g, $5.83 \mathrm{mmol})$ in water $(1 \mathrm{~mL})$ and the mixture was stirred at $0^{\circ} \mathrm{C}$ for $30 \mathrm{~min}$. After removal of solvent under reduced pressure, the cesium salt was dissolved in DMF (20 mL). The solution was treated with benzyl bromide $(2.40 \mathrm{~mL}, 11.1 \mathrm{mmol})$ and the mixture was stirred at room temperature. After the reaction was completed, the mixture was quenched with $\mathrm{H}_{2} \mathrm{O}(10 \mathrm{~mL})$ and extracted with ethyl acetate (20 mL x 3). The combined organic layer was washed with $\mathrm{H}_{2} \mathrm{O}(10 \mathrm{~mL}$ x 5) and (10 mL), dried over $\mathrm{MgSO}_{4}$, filtered and evaporated in vacuo. The crude was purified by column chromatography on silica gel $(120 \mathrm{~mL}$, hexane:ethyl acetate $=15: 1)$ to provide $(2.23 \mathrm{~g}, 87 \%, 2$ steps $)$ as a colorless oil.

\section{(3S,4S)-3-hydroxy-4-methyloctanic acid (4)}




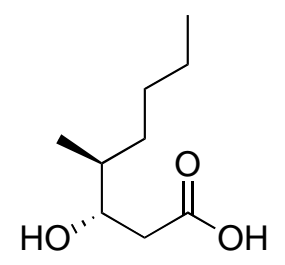

[ $]_{D}^{28}=-40$ (c 1.02, $\mathrm{CHCl}_{3}$ ); HREIMS : calcd. for $\mathrm{C}_{9} \mathrm{H}_{19} \mathrm{O}_{3}[\mathrm{M}+\mathrm{H}]^{+}$: 175.1334, found: 175.1341; IR (neat) :. 3473 , 2958, 2929, 2859, 1712, 1461, 1407, 1380, 1280, $1184 \mathrm{~cm}^{-1} ;{ }^{1} \mathrm{H}$ NMR (300 MHz, $\left.\mathrm{CDCl}_{3}\right) \delta(\mathrm{ppm}): 3.98(\mathrm{ddd}, j=7.5,5.0,4.5 \mathrm{~Hz}, 1 \mathrm{H}), 2.82(\mathrm{~d}, j=16.0 \mathrm{~Hz}, 1 \mathrm{H}), 2.52(\mathrm{dd}, j=16.0,5.0$ Hz, 1H), 1.60-1.41 (m, 2H), 1.41-1.21 (m, 4H), $1.16(\mathrm{~m}, 1 \mathrm{H}), 0.94(\mathrm{~d}, j=6.5 \mathrm{~Hz}, 3 \mathrm{H}), 0.91(\mathrm{t}, j=7.0$ $\mathrm{Hz}, 3 \mathrm{H}) ;{ }^{13} \mathrm{C}$ NMR (67.9 MHz, $\left.\mathrm{CDCl}_{3}\right) \delta(\mathrm{ppm}): 14.0,14.2,22.9,29.3,32.3,38.0,38.6,71.4,178.1$.

\section{Benzyl (3S,4S)-3-hydroxy-4-methyloctanoate (13)}

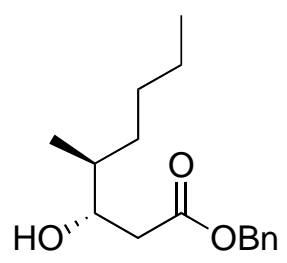

$[\alpha]_{\mathrm{D}}{ }^{25}=-31$ (c 0.82, $\mathrm{CHCl}_{3}$ ); HRFABMS : calcd. for $\mathrm{C}_{16} \mathrm{H}_{25} \mathrm{O}_{3}[\mathrm{M}+\mathrm{H}]^{+}:$265.1804, found: 265.1792; IR (neat) : 3473, 2956, 2927, 2857, 1727, 1455, 1380, 1278, $1168 \mathrm{~cm}^{-1} ;{ }^{1} \mathrm{H}$ NMR $\left(270 \mathrm{MHz}, \mathrm{CDCl}_{3}\right) \delta$ (ppm) : 7.40-7.30 (m, 5H), 5.15 (s, 2H), 3.95 (m, 1H), 2.70 (d, $j=16.2 \mathrm{~Hz}, 1 \mathrm{H}), 2.52$ (d, $j=16.2 \mathrm{~Hz}$, 1H), 1.54-1.38 (m, 2H), 1.37-1.18 (m, 3H), 1.15 (m, 1H), 0.90 (d, $j=7.0 \mathrm{~Hz}, 3 \mathrm{H}), 0.89$ (t, $j=7.2 \mathrm{~Hz}$, 3H); ${ }^{13} \mathrm{C}$ NMR (67.9 MHz, $\left.\mathrm{CDCl}_{3}\right) \delta(\mathrm{ppm}): 14.0,14.2,22.9,29.4,32.4,38.0,38.8,66.5,71.2,128.2$, 128.3 (x 2), 128.6 (x 2), 135.6, 173.2.

\section{Methyl (3S,4S)-3-hydroxy-4-methyloctanoate (5)}

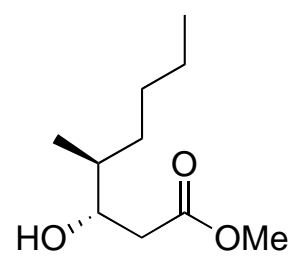


To a solution of (3S,4S)-3-hydroxy-4-methyloctanic acid (4) (200 mg, $1.15 \mu \mathrm{mol})$ in CH2Cl2 (10 mL) was added methanol $(0.47 \mathrm{~mL}, 11.5 \mathrm{mmol})$ a catalytic amount of concentrated sulfuric acid. The reaction mixture was warmed to $40^{\circ} \mathrm{C}$. After stirring for $15 \mathrm{~h}$, the mixture was poured into saturated aqueous $\mathrm{NaHCO}_{3}$ and the phases were separated. The organic layer was washed with brine (100 mL), dried over $\mathrm{MgSO}_{4}$, filtered and evaporated in vacuo. The crude was purified by column chromatography on silica gel $(120 \mathrm{~mL}$, hexane:ethyl acetate $=5: 1)$ to provide $(214 \mathrm{mg}, 93 \%)$ as a colorless oil.; [ $]_{\mathrm{D}}^{28}=$ -38 (c 0.98, $\left.\mathrm{CHCl}_{3}\right) ;{ }^{1} \mathrm{H} \mathrm{NMR}\left(270 \mathrm{MHz}, \mathrm{CDCl}_{3}\right) \delta(\mathrm{ppm}): 3.92$ (m, 1H), 3.69 (s, 3H), 2.78 (brs, 1H), 2.45-2.43 (m, 2H), 1.52-1.39 (m, 2H), 1.35-1.19 (m, 3H), $1.13(\mathrm{~m}, 1 \mathrm{H}), 0.88(\mathrm{~d}, j=6.6 \mathrm{~Hz}, 3 \mathrm{H}), 0.87(\mathrm{t}$, $j=7.2 \mathrm{~Hz}, 3 \mathrm{H}) ;{ }^{13} \mathrm{C} \mathrm{NMR}\left(67.9 \mathrm{MHz}, \mathrm{CDCl}_{3}\right) \delta(\mathrm{ppm}): 14.0,14.2,22.9,29.4,32.4,38.0,38.6,51.7$, 71.2, 173.9

\section{Benzyl}

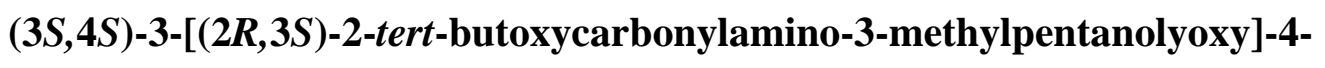

\section{methyloctanoate}

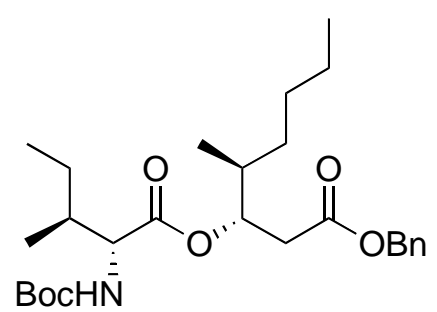

A mixture of Boc-D-allo-isoleucine $(1.19 \mathrm{~g}, 5.14 \mathrm{mmol})$ and benzyl ester (1.13 g, $4.29 \mathrm{mmol})$ in $\mathrm{CH}_{2} \mathrm{Cl}_{2}(45 \mathrm{~mL})$ was treated with DCC $(1.77 \mathrm{~g}, 8.58 \mathrm{mmol})$ in the presence of DMAP (52. $0 \mathrm{mg}, 429$ mol) and the resulting mixture was stirred at $0{ }^{\circ} \mathrm{C}$. After stirring for $22 \mathrm{~h}$, the resulting urea was removed by filtration and washed with a small amount of $\mathrm{CH}_{2} \mathrm{Cl}_{2}$. The combined solvent was washed with $1 \mathrm{M}$ hydrogen chloride $(10 \mathrm{~mL})$ and brine $(10 \mathrm{~mL})$, dried over $\mathrm{MgSO}_{4}$, filtered and evaporated in vacuo. The crude product was purified by column chromatography on silica gel (200 mL, hexane:ethyl acetate $=15: 1)$ to provide $(1.72 \mathrm{~g}, 84 \%)$ as a colorless oil.; []$_{\mathrm{D}}{ }^{24}=-14$ (c 1.00, $\left.\mathrm{CHCl}_{3}\right)$; HRFABMS : calcd. for $\mathrm{C}_{27} \mathrm{H}_{43} \mathrm{NO}_{6} \mathrm{Na}[\mathrm{M}+\mathrm{Na}]^{+}$: 500.2988, found: 500.3009; IR (neat) : 3445, 3382, 2966, 2934, 2878, 1722, $1500 \mathrm{~cm}^{-1} ;{ }^{1} \mathrm{H}$ NMR (270 MHz, $\left.\mathrm{CDCl}_{3}\right) \delta(\mathrm{ppm}): 7.37-7.31(\mathrm{~m}, 5 \mathrm{H}), 5.29(\mathrm{dt}, j=7.9,4.6$ 
Hz, 1H), 5.12 (d, $j=12.2 \mathrm{~Hz}, 1 \mathrm{H}), 5.06$ (d, $j=12.2 \mathrm{~Hz}, 1 \mathrm{H}), 4.96$ (d, $j=9.2 \mathrm{~Hz}, 1 \mathrm{H}), 4.31$ (dd, $j=9.2$,

3.6 Hz, 1H), 2.67 (dd, $j=15.8,8.3 \mathrm{~Hz}, 1 \mathrm{H}), 2.56$ (dd, $j=15.8,5.0 \mathrm{~Hz}, 1 \mathrm{H}), 1.79(\mathrm{~m}, 1 \mathrm{H}), 1.73(\mathrm{~m}, 1 \mathrm{H})$, 1.44 (s, 9H), 1.44-1.13 (m, 8H), 0.92 (d, $j=6.9 \mathrm{~Hz}, 3 \mathrm{H}), 0.91$ (t, $j=7.3 \mathrm{~Hz}, 3 \mathrm{H}), 0.90$ (t, $j=6.3 \mathrm{~Hz}$, 3H), $0.79(\mathrm{~d}, j=6.6 \mathrm{~Hz}, 3 \mathrm{H}) ;{ }^{13} \mathrm{C} \mathrm{NMR}\left(67.9 \mathrm{MHz}, \mathrm{CDCl}_{3}\right) \delta(\mathrm{ppm}): 11.7,14.0,14.2,14.5,22.7,26.1$, 28.3 (x 3), 29.3, 32.0, 36.4 (x 2), 37.5, 56.7, 66.5, 74.6, 79.6, 128.3 (x 2), 128.4, 128.5 (x 2), 135.6, $155.7,170.4,172.1$

(3S,4S)-3-[(2R,3S)-2-tert-butoxycarbonylamino-3-methylpentanolyoxy]-4-methyloctanoic acid (14)

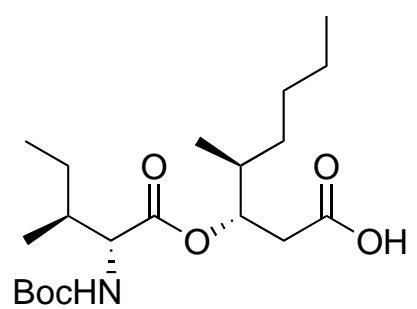

To a solution of benzyl ester (1.82 g, $3.41 \mathrm{mmol})$ in ethanol (34 mL) was added 10\% palladium on activated carbon (180 mg) and the suspension was vigorously stirred under an atmosphere of hydrogen. After stirring for $2 \mathrm{~h}$, the catalyst was filtered by a pad of Celite and washed with $\mathrm{CHCl}_{3}(100 \mathrm{~mL})$. The solvent was removed in vacuo. The crude was purified by column chromatography on silica gel (100 $\mathrm{mL}$, hexane:ethyl acetate $=3: 1$ to $1: 1)$ to provide $\left(1.51 \mathrm{~g}\right.$, quant.) as a white powder (14).; mp 85-87 ${ }^{\circ} \mathrm{C}$; []$_{\mathrm{D}}{ }^{24}=-27$ (c 1.00, $\mathrm{CHCl}_{3}$ ); HRFABMS : calcd. for $\mathrm{C}_{20} \mathrm{H}_{37} \mathrm{NO}_{6} \mathrm{Na}[\mathrm{M}+\mathrm{Na}]^{+}$: 432.2338, found: 432.2341; IR (KBr) : 3332, 2967, 2931, 2856, 1758, 1720, 1662, 1463, 1409, 1367, 1284, $1164 \mathrm{~cm}^{-1} ;{ }^{1} \mathrm{H}$ NMR (270 MHz, $\left.\mathrm{CDCl}_{3}\right) \delta(\mathrm{ppm}): 5.25(\mathrm{dt}, j=7.6,4.3 \mathrm{~Hz}, 1 \mathrm{H}), 4.99(\mathrm{~d}, j=9.2 \mathrm{~Hz}, 1 \mathrm{H}), 4.31(\mathrm{dd}, j=$ 9.2, 3.6 Hz, 1H), 2.63 (dd, $j=15.8,8.3 \mathrm{~Hz}, 1 \mathrm{H}), 2.54$ (dd, $j=15.8,5.0 \mathrm{~Hz}, 1 \mathrm{H}), 1.83$ (m, $1 \mathrm{H}), 1.75$ (m, 1H), 1.42 (s, 9H), 1.42-1.07 (m, 8H), $0.93(\mathrm{~d}, j=7.2 \mathrm{~Hz}, 3 \mathrm{H}), 0.89(\mathrm{t}, j=6.9 \mathrm{~Hz}, 3 \mathrm{H}), 0.87(\mathrm{t}, j=6.9$ $\mathrm{Hz}, 3 \mathrm{H}), 0.79(\mathrm{~d}, j=6.9 \mathrm{~Hz}, 3 \mathrm{H}) ;{ }^{13} \mathrm{C} \mathrm{NMR}\left(67.8 \mathrm{MHz}, \mathrm{CDCl}_{3}\right) \delta(\mathrm{ppm}): 11.6,13.9,14.1,14.4,22.7$, 26.2, 28.2 (x 3), 29.2, 31.9, 36.0, 36.2, 37.4, 56.7, 74.3, 79.6, 155.7, 172.2, 176.2. 


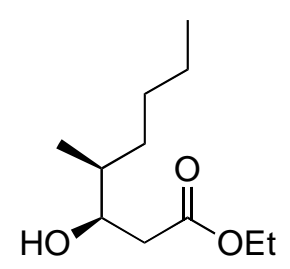

$\mathrm{RuCl}_{2}(\mathrm{~S})$-BINAP (36.0 mg, $39.7 \mu \mathrm{mol}$ ) was placed in a glass vessel under nitrogen, then a solution of $3(795 \mathrm{mg}, 3.97 \mu \mathrm{mol})$ in degassed ethanol $(5 \mathrm{~mL})$ was added to this vessel, and placed in $50 \mathrm{~mL}$ stainless steel autoclave. Hydrogen was pressurized to 90 atm and the mixture was stirred at $45^{\circ} \mathrm{C}$ for 44 h. The solvent was removed in reduced pressure. The crude was filtered through florizil. The filtrate was purified by column chromatography on silica gel (40 mL, hexane:ethyl acetate $=10: 1$ ) to provide 8 (753 mg, 94\%) as a colorless oil.; $[\alpha]_{\mathrm{D}}{ }^{29}=+18$ (c 1.02, $\mathrm{CHCl}_{3}$ ); HRFABMS : calcd for $\mathrm{C}_{11} \mathrm{H}_{23} \mathrm{O}_{3}$ $[\mathrm{M}+\mathrm{H}]^{+}:$203.1647, found: 203.1638; IR (neat): 3482, 2958, 2931, 2859, 1735, 1465, 1373, 1278, 1180, $1031 \mathrm{~cm}^{-1} ;{ }^{1} \mathrm{H}$ NMR (270 MHz, $\left.\mathrm{CDCl}_{3}\right) \delta(\mathrm{ppm}): 4.17$ (q, $\left.j=7.2 \mathrm{~Hz}, 2 \mathrm{H}\right), 3.86$ (ddd, $j=9.2,5.6,3.3$ Hz, 1H), 2.46 (dd, $j=16.2,3.3 \mathrm{~Hz}, 1 \mathrm{H}), 2.38$ (dd, $j=16.2,9.2 \mathrm{~Hz}, 1 \mathrm{H}), 1.56$ (m, 1H), 1.48-1.13 (m, 9H), $0.89(\mathrm{t}, j=6.9 \mathrm{~Hz}, 3 \mathrm{H}), 0.88(\mathrm{~d}, j=6.9 \mathrm{~Hz}, 3 \mathrm{H}) ;{ }^{13} \mathrm{C} \mathrm{NMR}\left(67.9 \mathrm{MHz}, \mathrm{CDCl}_{3}\right) \delta(\mathrm{ppm}): 14.0$ 14.1, 14.8, 22.9, 29.3, 31.9, 37.8, 38.1, 60.6, 71.8, 173.6.

\section{(3R,4S)-3-hydroxy-4-methyloctanic acid (9) and benzyl (3R,4S)-3-hydroxy-4-methyloctanoate}

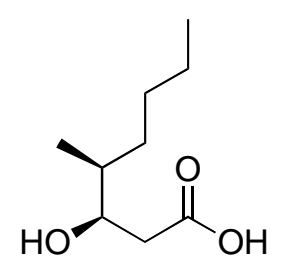

Ethyl (3R,4S)-3-hydroxy-4-methyloctanoate (8) (1.10 g, $5.46 \mathrm{mmol})$ was converted to (3R,4S)-3hydroxy-4-methyloctanic acid (9) and Benzyl (3R,4S)-3-hydroxy-4-methyloctanoate (1.39 g, $98 \%, 2$ steps) by the same procedure as that described above for the formation of Benzyl (3S,4S)-3-hydroxy-4methyloctanoate (13); $[\alpha]_{\mathrm{D}}^{25}=+18$ (c 1.16, $\mathrm{CHCl}_{3}$ ); HREIMS : calcd. for $\mathrm{C}_{9} \mathrm{H}_{19} \mathrm{O}_{3}[\mathrm{M}+\mathrm{H}]^{+}$: 175.1334 , found: 175.1331; IR (neat) :. 3471, 2958, 2929, 2859, 1712, 1461, 1407, 1380, 1280, $1184 \mathrm{~cm}^{-1} ;{ }^{1} \mathrm{H}$ NMR (300 MHz, $\left.\mathrm{CDCl}_{3}\right) \delta(\mathrm{ppm}): 3.91$ (ddd, $\left.j=9.0,5.0,3.0 \mathrm{~Hz}, 1 \mathrm{H}\right), 2.56(\mathrm{dd}, j=16.0,3.0 \mathrm{~Hz}, 1 \mathrm{H})$, 
2.52 (dd, $j=16.0,5.0 \mathrm{~Hz}, 1 \mathrm{H}), 1.63$ (m, 1H), 1.47 (m, 1H), 1.40-1.09 (m, 5H), 0.92 (d, $j=6.5 \mathrm{~Hz}, 3 \mathrm{H})$,

$0.91(\mathrm{t}, j=7.0 \mathrm{~Hz}, 3 \mathrm{H}) ;{ }^{13} \mathrm{C} \mathrm{NMR}\left(67.9 \mathrm{MHz}, \mathrm{CDCl}_{3}\right) \delta(\mathrm{ppm}): 14.0,14.8,22.9,29.3,31.9,37.6,38.1$, 71.9, 178.2.

\section{Benzyl (3R,4S)-3-hydroxy-4-methyloctanoate}

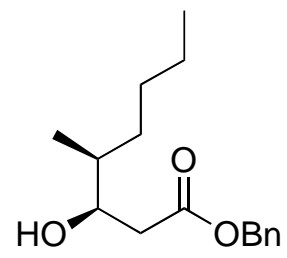

$[\alpha]_{\mathrm{D}}{ }^{25}=+17$ (c 1.17, $\left.\mathrm{CHCl}_{3}\right)$; HRFABMS : calcd. for $\mathrm{C}_{16} \mathrm{H}_{25} \mathrm{O}_{3}[\mathrm{M}+\mathrm{H}]^{+}$: 265.1804, found: 265.1808; IR (neat) : 3451, 2958, 2929, 2857, 1735, 1455, 1380, 1274, $1166 \mathrm{~cm}^{-1} ;{ }^{1} \mathrm{H}$ NMR (270 MHz, $\left.\mathrm{CDCl}_{3}\right) \delta$ (ppm) : 7.39-7.32 (m, 5H), 5.16 (s, 2H), 3.90 (ddd, $j=8.9,5.6,3.3 \mathrm{~Hz}, 1 \mathrm{H}), 2.52$ (dd, $j=16.2,3.3 \mathrm{~Hz}$ 1H), 2.45 (dd, $j=16.2,8.9 \mathrm{~Hz}, 1 \mathrm{H}), 1.60(\mathrm{~m}, 1 \mathrm{H}), 1.50-1.06(\mathrm{~m}, 6 \mathrm{H}), 0.89(\mathrm{t}, j=6.9 \mathrm{~Hz}, 3 \mathrm{H}), 0.88(\mathrm{~d}, j$ = 7.0 Hz, 3H); ${ }^{13} \mathrm{C}$ NMR (67.9 $\left.\mathrm{MHz}, \mathrm{CDCl}_{3}\right) \delta(\mathrm{ppm}): 14.1,14.9,22.9,29.3,31.9,37.8,38.1,66.5$, 71.8, 128.3 , 128.4(x 2), 128.6 (x 2), 135.6, 173.4.

\section{Methyl (3R,4S)-3-hydroxy-4-methyloctanoate (10)}

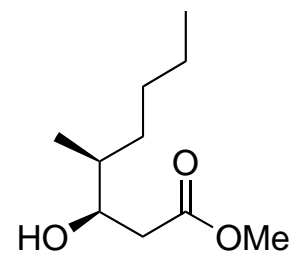

(3R,4S)-3-hydroxy-4-methyloctanoic acid (9) (110 mg, $634 \mu \mathrm{mol}$ ) was converted to methyl $(3 R, 4 S)$-3-hydroxy-4-methyloctanoate (10) (115 $\mathrm{mg}, 98 \%)$ by the same procedure as that described above for the formation of methyl $(3 S, 4 S)$-3-hydroxy-4-methyloctanoate (5).; []$_{\mathrm{D}}^{29}=+18$ (c 1.02, $\left.\mathrm{CHCl}_{3}\right) ;{ }^{1} \mathrm{H}$ NMR $\left(270 \mathrm{MHz}, \mathrm{CDCl}_{3}\right) \delta(\mathrm{ppm}): 3.87$ (m, 1H), 3.68 (s, 3H), 2.92 (brs, 1H), 2.46 (dd, $j=$ 16.1, 3.3 Hz, 1H), 2.37 (dd, $j=16.2,8.9$ Hz, 1H), 1.55 (m, 1H), 1.44 (m, 1H), 1.33-1.20 (m, 3H), 1.11 
(m, 1H), $0.88(\mathrm{t}, j=6.6 \mathrm{~Hz}, 3 \mathrm{H}), 0.86(\mathrm{~d}, j=6.6 \mathrm{~Hz}, 3 \mathrm{H}) ;{ }^{13} \mathrm{C} \mathrm{NMR}\left(67.9 \mathrm{MHz}, \mathrm{CDCl}_{3}\right) \delta(\mathrm{ppm}): 14.0$, 14.8, 22.9, 29.3, 31.9, 37.6, 38.1, 51.7, 71.7, 173.9 .

Benzyl

\section{methyloctanoate}

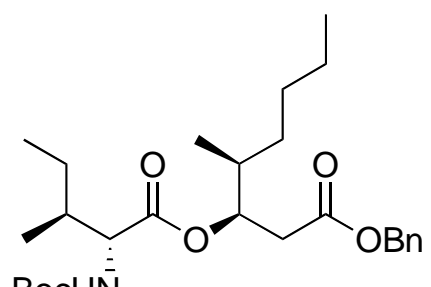

BocH
(3R,4S)-3-[(2R,3S)-2-tert-butoxycarbonylamino-3-methylpentanolyoxy]-4-

A mixture of Boc-D-allo-isoleucine (340 mg, $1.46 \mathrm{mmol}$ ) and Benzyl (3R,4S)-3-hydroxy-4methyloctanoate (340 mg, $1.13 \mathrm{mmol})$ in $\mathrm{CH}_{2} \mathrm{Cl}_{2}(11 \mathrm{~mL})$ was treated with DCC (700 mg, $\left.3.39 \mathrm{mmol}\right)$ in the presence of DMAP $(14.0 \mathrm{mg}, 11.3 \mu \mathrm{mol})$ and the resulting mixture was stirred at $0{ }^{\circ} \mathrm{C}$. After stirring for $16 \mathrm{~h}$, the resulting urea was removed by filtration and washed with a small amount of $\mathrm{CH}_{2} \mathrm{Cl}_{2}$. The combined solvent was washed with $1 \mathrm{M}$ hydrogen chloride $(10 \mathrm{~mL})$ and brine $(10 \mathrm{~mL})$, dried over $\mathrm{MgSO}_{4}$, filtered and evaporated in vacuo. The crude product was purified by column chromatography on silica gel (100 mL, hexane:ethyl acetate $=15: 1$ to $10: 1)$ to provide (528 mg, $98 \%)$ as a colorless oil.; HRFABMS : calcd. for $\mathrm{C}_{27} \mathrm{H}_{43} \mathrm{NO}_{6} \mathrm{Na}[\mathrm{M}+\mathrm{Na}]^{+}$: 500.2988, found: 500.2992; IR (neat) : 3445, 3382, 2966, 2934, 2878, 1722, $1500 \mathrm{~cm}^{-1} ;{ }^{1} \mathrm{H}$ NMR $\left(270 \mathrm{MHz}, \mathrm{CDCl}_{3}\right) \delta(\mathrm{ppm}): 7.36-$ 7.29 (m, 5H), 5.29 (dt, $j=8.2,4.6 \mathrm{~Hz}, 1 \mathrm{H}), 5.11$ (s, 2H), 4.94 (d, j= $9.2 \mathrm{~Hz}, 1 \mathrm{H}), 4.34$ (dd, $j=9.2,3.3$ Hz, 1H), 2.64 (dd, $j=15.8,8.2$ Hz, 1H), 2.55 (dd, $j=15.8,4.6 \mathrm{~Hz}, 1 \mathrm{H}), 1.91$ (m, 1H), 1.80 (m, 1H), 1.44 (s, 9H), 1.39-1.07 (m, 8H), 0.94 (t, $j=7.2 \mathrm{~Hz}, 3 \mathrm{H}), 0.89$ (d, $j=7.3 \mathrm{~Hz}, 3 \mathrm{H}), 0.88$ (t, $j=6.6 \mathrm{~Hz}$, 3H), $0.80(\mathrm{~d}, j=7.0 \mathrm{~Hz}, 3 \mathrm{H}) ;{ }^{13} \mathrm{C} \mathrm{NMR}\left(67.9 \mathrm{MHz}, \mathrm{CDCl}_{3}\right) \delta(\mathrm{ppm}): 11.7,14.0,14.2,14.7,22.7,26.3$, 28.3 (x 3), 29.2, 31.8, 35.5, 35.9, 37.7, 56.9, 66.6, 75.0, 79.5, 128.3 (x 2), 128.4, 128.5 (x 2), 135.7, 155.6, 170.4, 171.9 .

(3R,4S)-3-[(2R,3S)-2-tert-butoxycarbonylamino-3-methylpentanolyoxy]-4-methyloctanoic acid (16) 


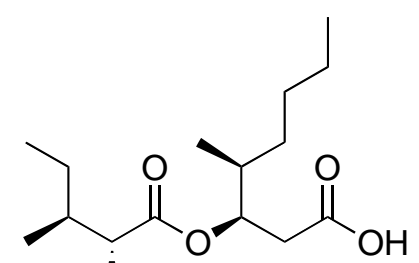

BocHN̄

To a solution of benzyl ester (527 mg, $1.10 \mathrm{mmol})$ in ethanol $(11 \mathrm{~mL})$ was added $10 \%$ palladium on activated carbon (50 mg) and the suspension was vigorously stirred under an atmosphere of hydrogen. After stirring for $22 \mathrm{~h}$, the catalyst was filtered by a pad of Celite and washed with $\mathrm{CHCl}_{3}(100 \mathrm{~mL})$. The solvent was removed in vacuo. The crude was purified by column chromatography on silica gel (60 mL, hexane:ethyl acetate $=3: 1$ to $1: 1)$ to provide $(401 \mathrm{mg}, 94 \%)$ as a white powder.; $[\alpha]_{\mathrm{D}}{ }^{26}=+8.7(\mathrm{c}$ 1.00, $\mathrm{CHCl}_{3}$ ); HRFABMS : calcd. for $\mathrm{C}_{20} \mathrm{H}_{37} \mathrm{NO}_{6} \mathrm{Na}[\mathrm{M}+\mathrm{H}]^{+}$: 410.2519, found: 410.2517; IR (KBr) : 3330, 2964, 2933, 2861, 1737, 1716, 1666, 1504, 1461, 1403, 1367, 1249, $1162 \mathrm{~cm}^{-1}$; ${ }^{1} \mathrm{H}$ NMR (270 $\left.\mathrm{MHz}, \mathrm{CDCl}_{3}\right) \delta(\mathrm{ppm}): 5.24(\mathrm{dt}, j=7.9,5.0 \mathrm{~Hz}, 1 \mathrm{H}), 4.96(\mathrm{~d}, j=9.2 \mathrm{~Hz}, 1 \mathrm{H}), 4.31$ (dd, $j=9.2,3.6 \mathrm{~Hz}$, 1H), 2.64 (dd, $j=16.0,7.9 \mathrm{~Hz}, 1 \mathrm{H}), 2.56$ (dd, $j=16.0,5.0 \mathrm{~Hz}, 1 \mathrm{H}), 1.95-1.82$ (m, 2H), 1.44 (s, $9 \mathrm{H}$ ), 1.50-1.09 (m, 8H), $0.94(\mathrm{t}, j=7.3 \mathrm{~Hz}, 3 \mathrm{H}), 0.89$ (d, $j=6.9 \mathrm{~Hz}, 3 \mathrm{H}), 0.87$ (t, $j=6.9 \mathrm{~Hz}, 3 \mathrm{H}), 0.84(\mathrm{~d}, j=$ $6.9 \mathrm{~Hz}, 3 \mathrm{H}) ;{ }^{13} \mathrm{C}$ NMR (67.8 MHz, $\left.\mathrm{CDCl}_{3}\right) \delta(\mathrm{ppm}): 11.7,14.0,14.2,14.6,22.8,26.2,28.3$ (x 3), 29.1, 31.8, 35.0, 35.8, 37.6, 57.0, 74.8, 79.8, 155.8, 172.0, 175.5.

\section{Ethyl (R)-3-oxo-4-methyloctanoate}

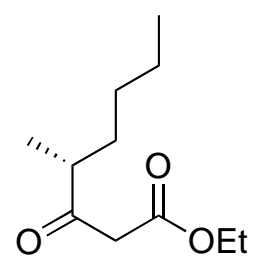

(4R)-3-[(2'R)-2'-Methylhexanoyl]-4-isopropyloxazolidin-2-one (1.00 g, $4.14 \mathrm{mmol})$ was converted to Ethyl (R)-3-oxo-4-methyloctanoate (620 mg, 64\%) by the same procedure as that described above for the formation of Ethyl (R)-3-oxo-4-methyloctanoate.; [ $]_{\mathrm{D}}^{29}=+12$ (c 1.11, $\mathrm{CHCl}_{3}$ ); HRFABMS : calcd. for $\mathrm{C}_{11} \mathrm{H}_{21} \mathrm{O}_{3}[\mathrm{M}+\mathrm{H}]^{+}$: 201.1491, found: 201.1494. 


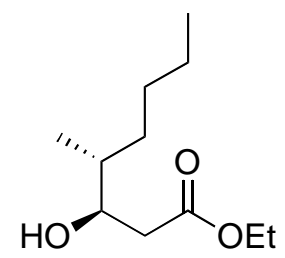

Ethyl (R)-3-oxo-4-methyloctanoate (456 mg, $2.28 \mathrm{mmol}$ ) was converted to Ethyl (3R,4R)-3hydroxy-4-methyloctanoate (433 mg, 94\%) by the same procedure as that described above for the

formation of Ethyl $(3 R, 4 S)$-3-hydroxy-4-methyloctanoate (8).; [ $]_{\mathrm{D}}^{29}=+30$ (c 1.26, $\mathrm{CHCl}_{3}$ ); HRFABMS : calcd for $\mathrm{C}_{11} \mathrm{H}_{23} \mathrm{O}_{3}[\mathrm{M}+\mathrm{H}]^{+}$: 203.1647, found: 203.1641.

(3R,4R)-3-hydroxy-4-methyloctanic acid (ent-4) and Benzyl (3R,4R)-3-hydroxy-4methyloctanoate

Ethyl (3R,4R)-3-hydroxy-4-methyloctanoate (135 mg, 670 mol) was converted to (3R,4R)-3hydroxy-4-methyloctanic acid (ent-4) and Benzyl (3R,4R)-3-hydroxy-4-methyloctanoate (176 mg, quant. 2 steps) by the same procedure as that described above for the formation of Benzyl (3S,4S)-3hydroxy-4-methyloctanoate (13).

(3R,4R)-3-hydroxy-4-methyloctanic acid (ent-4)<smiles>CCCC[C@H](C)[C@H](O)CC(=O)O</smiles>

[]$_{\mathrm{D}}^{25}=+40$ (c 0.99, $\mathrm{CHCl}_{3}$ ); HREIMS : calcd. for $\mathrm{C}_{9} \mathrm{H}_{19} \mathrm{O}_{3}[\mathrm{M}+\mathrm{H}]^{+}:$: 175.1334, found: 175.1339.

Benzyl (3R,4R)-3-hydroxy-4-methyloctanoate 


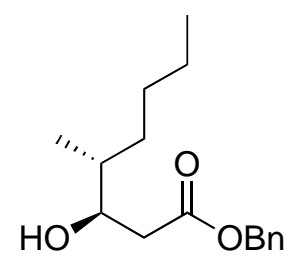

[]$_{\mathrm{D}}^{25}=+31$ (c 1.41, $\mathrm{CHCl}_{3}$ ); HRFABMS : calcd. for $\mathrm{C}_{16} \mathrm{H}_{25} \mathrm{O}_{3}[\mathrm{M}+\mathrm{H}]^{+}$: 265.1804, found: 265.1799.

\section{Methyl (3R,4R)-3-hydroxy-4-methyloctanoate (ent-5)}<smiles>CCCC[C@H](C)[C@H](O)CC(=O)OC</smiles>

(3R,4R)-3-hydroxy-4-methyloctanoic acid (ent-4) (130 mg, $773 \mathrm{mmol}$ ) was converted to methyl (3R,4R)-3-hydroxy-4-methyloctanoate (ent-5) (122 mg, 87\%) by the same procedure as that described above for the formation of methyl $(3 S, 4 S)$-3-hydroxy-4-methyloctanoate (5).; [ $]_{\mathrm{D}}{ }^{27}=+39$ (c 0.93 , $\left.\mathrm{CHCl}_{3}\right)$

\section{Benzyl}

(3R,4R)-3-[(2R,3S)-2-tert-butoxycarbonylamino-3-methylpentanolyoxy]-4-

\section{methyloctanoate}<smiles>CCCC[C@H](C)[C@H](CC(=O)OCc1ccccc1)OC(=O)[C@H](N)C(C)CC(C)(C)C</smiles>

Benzyl (3R,4R)-3-hydroxy-4-methyloctanoate (443 mg, $1.67 \mathrm{mmol})$ was converted to Benzyl (3R,4R)-3-[(2R,3S)-2-tert-butoxycarbonylamino-3-methylpentanolyoxy]-4-methyloctanoate (688 mg, 86\%) by the same procedure as that described above for the formation of Benzyl $(3 S, 4 S)-3-[(2 R, 3 S)-2-$ tert-butoxycarbonylamino-3-methylpentanolyoxy]-4-methyloctanoate; HRFABMS : calcd. for $\mathrm{C}_{27} \mathrm{H}_{44} \mathrm{NO}_{6} \mathrm{Na}[\mathrm{M}+\mathrm{H}]^{+}:$178.3169, found: 178.3153; IR (neat) $\lambda \operatorname{maxcm}^{-1}: 3445,3382,2966,2934$, 
2878, 1722, 1500; ${ }^{1} \mathrm{H}$ NMR (270 MHz, $\left.\mathrm{CDCl}_{3}\right) \delta(\mathrm{ppm}):$ 7.36-7.30 (m, 5H), 5.29 (ddd, $j=$ 7.9, 5.3, 3.6

Hz, 1H), 5.10 (s, 2H), 4.95 (d, j= 9.2 Hz, 1H), 4.35 (dd, j = 9.2, 3.6 Hz, 1H), 2.69 (dd, $j=15.5,7.9$ Hz, 1H), 2.57 (dd, $j=15.5,5.3$ Hz, 1H), 1.88 (m, 1H), 1.71 (m, 1H), 1.44 (s, 9H), 1.47-1.07 (m, 8H), 0.94 (t, $j=7.3 \mathrm{~Hz}, 3 \mathrm{H}), 0.91(\mathrm{~d}, j=6.9 \mathrm{~Hz}, 3 \mathrm{H}), 0.86(\mathrm{t}, j=6.9 \mathrm{~Hz}, 3 \mathrm{H}), 0.80(\mathrm{~d}, j=6.9 \mathrm{~Hz}, 3 \mathrm{H}) ;{ }^{13} \mathrm{C} \mathrm{NMR}$ $\left(67.9 \mathrm{MHz}, \mathrm{CDCl}_{3}\right) \delta(\mathrm{ppm}): 11.7,13.9,14.1,14.3,22.7,26.3,28.3$ (x 3), 29.3, 32.3, 36.1, 36.6, 37.7, 56.8, 66.6, 74.3, 79.5, 128.4 (x 3), 128.5 (x 2), 135.7, 155.6, 170.3, 172.0.

\section{(3R,4R)-3-[(2R,3S)-2-tert-butoxycarbonylamino-3-methylpentanolyoxy]-4-methyloctanoic acid} (15)

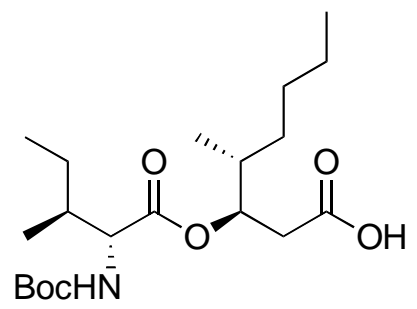

Benzyl (3R,4R)-3-[(2R,3S)-2-tert-butoxycarbonylamino-3-methylpentanolyoxy]-4-methyloctanoate (688 $\mathrm{mg}, \quad 1.44 \mathrm{mmol})$ was converted to $(3 R, 4 R)-3-[(2 R, 3 S)-2-$ tert-butoxycarbonylamino-3methylpentanolyoxy]-4-methyloctanoic acid (445 mg, 80\%) by the same procedure as that described above for the formation of $(3 S, 4 S)-3-[(2 R, 3 S)$-2-tert-butoxycarbonylamino-3-methylpentanolyoxy]-4methyloctanoic acid.; [ $]_{\mathrm{D}}{ }^{25}=+19$ (c 1.01, $\mathrm{CHCl}_{3}$ ); HRFABMS : calcd. for $\mathrm{C}_{20} \mathrm{H}_{37} \mathrm{NO}_{6} \mathrm{Na}[\mathrm{M}+\mathrm{Na}]^{+}$: 410.2519, found: 410.2517; IR (neat) : 3330, 2964, 2933, 2861, 1737, 1716, 1666, 1504, 1461, 1403, 1367, 1249, $1162 \mathrm{~cm}^{-1}$; ${ }^{1} \mathrm{H}$ NMR (270 MHz, $\left.\mathrm{CDCl}_{3}\right) \delta(\mathrm{ppm}): 5.24(\mathrm{dt}, j=8.3,4.6 \mathrm{~Hz}, 1 \mathrm{H}), 5.00(\mathrm{~d}, j=$ $9.5 \mathrm{~Hz}, 1 \mathrm{H}$ ), 4.33 (dd, $j=9.5,3.3 \mathrm{~Hz}, 1 \mathrm{H}), 2.61$ (dd, $j=16.2,8.3 \mathrm{~Hz}, 1 \mathrm{H}$ ), 2.53 (dd, $j=16.2,4.3 \mathrm{~Hz}$, 1H), 1.87-1.84 (m, 2H), 1.43 (s, 9H), 1.40-1.06 (m, 8H), 0.92 (t, $j=7.3 \mathrm{~Hz}, 3 \mathrm{H}), 0.89(\mathrm{~d}, j=6.6 \mathrm{~Hz}$, 3H), 0.88 (t, $j=7.0 \mathrm{~Hz}, 3 \mathrm{H}), 0.79(\mathrm{~d}, j=7.0 \mathrm{~Hz}, 3 \mathrm{H}) ;{ }^{13} \mathrm{C} \mathrm{NMR}\left(67.8 \mathrm{MHz}, \mathrm{CDCl}_{3}\right) \delta(\mathrm{ppm}): 11.7$, 13.9, 14.0, 14.5, 22.8, 26.2, 28.3 (x 3), 29.2, 32.0, 34.8, 35.9, 37.6, 56.7, 74.8, 79.7, 155.8, 172.2, 176.3.

\section{Ethyl (3S,4R)-3-hydroxy-4-methyloctanoate}


<smiles>CCCC[C@H](C)[C@@H](O)CC(=O)OCC</smiles>

Ethyl (R)-3-oxo-4-methyloctanoate (910 mg, $4.54 \mathrm{mmol}$ ) was converted to Ethyl (3S,4R)-3hydroxy-4-methyloctanoate (748 $\mathrm{mg}, 82 \%)$ by the same procedure as that described above for the formation of Ethyl (3R,4S)-3-hydroxy-4-methyloctanoate (8); [ $]_{\mathrm{D}}^{29}=-16$ (c 1.01, $\mathrm{CHCl}_{3}$ ); HRFABMS : calcd for $\mathrm{C}_{11} \mathrm{H}_{23} \mathrm{O}_{3}[\mathrm{M}+\mathrm{H}]^{+}$: 203.1647, found: 203.1645.

\section{(3S,4R)-3-hydroxy-4-methyloctanic acid (ent-9) and Benzyl (3S,4R)-3-hydroxy-4-} methyloctanoate

Ethyl (3S,4R)-3-hydroxy-4-methyloctanoate (330 mg, 670 mol) was converted to (3S,4R)-3hydroxy-4-methyloctanic acid (ent-9) and Benzyl (3S,4R)-3-hydroxy-4-methyloctanoate (176 mg, quant. 2 steps) by the same procedure as that described above for the formation of Benzyl (3S,4S)-3hydroxy-4-methyloctanoate (13).

\section{(3S,4R)-3-hydroxy-4-methyloctanic acid (ent-9)}<smiles>CCCC[C@H](C)[C@H](O)CC(=O)O</smiles>

[]$_{\mathrm{D}}^{29}=-16$ (c 1.01, $\mathrm{CHCl}_{3}$ ); HREIMS : calcd. for $\mathrm{C}_{9} \mathrm{H}_{19} \mathrm{O}_{3}[\mathrm{M}+\mathrm{H}]^{+}:$175.1334, found: 175.1334 .

\section{Benzyl (3S,4R)-3-hydroxy-4-methyloctanoate}<smiles>CCCC[C@H](C)[C@H](O)CC(=O)OCc1ccccc1</smiles> 
[ $]_{\mathrm{D}}{ }^{24}=-17$ (c 1.00, $\left.\mathrm{CHCl}_{3}\right)$; HRFABMS : calcd. for $\mathrm{C}_{16} \mathrm{H}_{25} \mathrm{O}_{3}[\mathrm{M}+\mathrm{H}]^{+}:$265.1804, found: 265.1806.

\section{Methyl (3S,4R)-3-hydroxy-4-methyloctanoate (ent-10)}

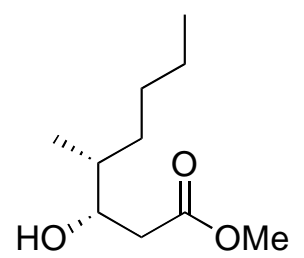

(3S,4R)-3-hydroxy-4-methyloctanoic acid (ent-9) (134 mg, $773 \mathrm{mmol}$ ) was converted to methyl (3S,4R)-3-hydroxy-4-methyloctanoate (128 mg, 87\%) by the same procedure as that described above for the formation of methyl $(3 S, 4 S)$-3-hydroxy-4-methyloctanoate (5); [ $]_{\mathrm{D}}^{27}=-17$ (c 1.02, $\mathrm{CHCl}_{3}$ )

\section{Benzyl \\ (3S,4R)-3-[(2R,3S)-2-tert-butoxycarbonylamino-3-methylpentanolyoxy]-4-}

\section{methyloctanoate}

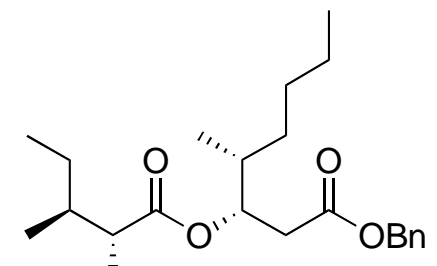

BocH $\overline{\bar{N}}$

Benzyl (3S,4R)-3-hydroxy-4-methyloctanoate (271 mg, $1.02 \mathrm{mmol})$ was converted to Benzyl (3S,4R)-3-[(2R,3S)-2-tert-butoxycarbonylamino-3-methylpentanolyoxy]-4-methyloctanoate (439 mg, $90 \%)$ by the same procedure as that described above for the formation of Benzyl (3S,4S)-3-[(2R,3S)-2tert-butoxycarbonylamino-3-methylpentanolyoxy]-4-methyloctanoate.; HRFABMS : calcd. for $\mathrm{C}_{27} \mathrm{H}_{43} \mathrm{NO}_{6} \mathrm{Na}[\mathrm{M}+\mathrm{Na}]^{+}:$500.2988, found: 500.2990; IR (neat) $\lambda \operatorname{maxcm}^{-1}: 3445,3382,2966,2934$, 2878, 1722, 1500; ${ }^{1} \mathrm{H}$ NMR (270 MHz, $\left.\mathrm{CDCl}_{3}\right) \quad \delta(\mathrm{ppm}): 7.37-7.29(\mathrm{~m}, 5 \mathrm{H}), 5.29$ (dt, $j=8.9,4.3 \mathrm{~Hz}$, 1H), 5.12 (d, $j=12.5 \mathrm{~Hz}, 1 \mathrm{H}), 5.06$ (d, $j=12.5 \mathrm{~Hz}, 1 \mathrm{H}), 4.97$ (d, $j=9.2 \mathrm{~Hz}, 1 \mathrm{H}), 4.32$ (dd, $j=9.2,3.3$ Hz, 1H), 2.63 (dd, $j=15.8,8.9$ Hz, 1H), 2.54 (dd, $j=15.8,4.3$ Hz, 1H), 1.87-1.05 1.80 (m, 2H), 1.44 (s, 9H), 1.41-1.05 (m, 8H), 0.92 (t, $j=7.2 \mathrm{~Hz}, 3 \mathrm{H}), 0.89$ (d, $j=6.9 \mathrm{~Hz}, 3 \mathrm{H}), 0.88(\mathrm{t}, j=6.9 \mathrm{~Hz}, 3 \mathrm{H}), 0.77$ $(\mathrm{d}, j=6.9 \mathrm{~Hz}, 3 \mathrm{H}) ;{ }^{13} \mathrm{C}$ NMR $\left(67.9 \mathrm{MHz}, \mathrm{CDCl}_{3}\right) \delta(\mathrm{ppm}): 11.7,14.0,14.1,14.6,22.7,26.2,28.3(\mathrm{x}$ 
3), 29.2, 32.0, 35.2, 35.9, 37.6, 56.7, 66.5, 75.1, 79.6, 128.3 (х 3), 128.6 (х 2), 135.6, 155.7, 170.6, 172.0 .

(3S,4R)-3-[(2R,3S)-2-tert-butoxycarbonylamino-3-methylpentanolyoxy]-4-methyloctanoic acid (17)

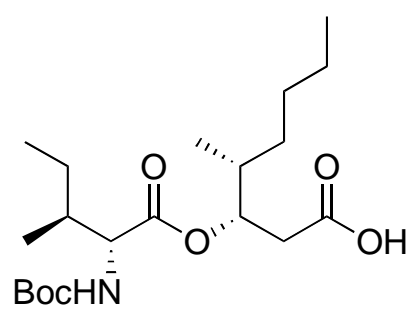

Benzyl (3S,4R)-3-[(2R,3S)-2-tert-butoxycarbonylamino-3-methylpentanolyoxy]-4-methyloctanoate (1.12 g, 2,34 mmol) was converted to $(3 S, 4 R)-3-[(2 R, 3 S)$-2-tert-butoxycarbonylamino-3methylpentanolyoxy]-4-methyloctanoic acid (752 $\mathrm{mg}, 83 \%$ ) by the same procedure as that described above for the formation of $(3 S, 4 S)-3-[(2 R, 3 S)$-2-tert-butoxycarbonylamino-3-methylpentanolyoxy]-4methyloctanoic acid. (14); mp 85-86 ${ }^{\circ} \mathrm{C}$; []$_{\mathrm{D}}^{23}=-18$ (c 1.01, $\mathrm{CHCl}_{3}$ ); HRFABMS : calcd. for $\mathrm{C}_{20} \mathrm{H}_{38} \mathrm{NO}_{6} \mathrm{Na}[\mathrm{M}+\mathrm{H}]^{+}:$388.2699, found: 388.2711; IR (neat) : 3330, 2962, 2931, 2862, 1749, 1720, 1666, 1504, 1459, 1403, 1367, 1259, $1164 \mathrm{~cm}^{-1} ;{ }^{1} \mathrm{H}$ NMR (270 MHz, $\left.\mathrm{CDCl}_{3}\right) \delta(\mathrm{ppm}): 5.27$ (ddd, $j=$ 7.6, 5.6, 3.6 Hz, 1H), 4.99 (d, $j=9.5 \mathrm{~Hz}, 1 \mathrm{H}), 4.34$ (dd, $j=9.5,3.6 \mathrm{~Hz}, 1 \mathrm{H}), 2.68$ (dd, $j=16.0,7.6 \mathrm{~Hz}$, 1H), 2.57 (dd, $j=16.0,5.6 \mathrm{~Hz}, 1 \mathrm{H}), 1.91$ (m, 1H), 1.76 (m, 1H), 1.44 (s, 9H), 1.49-1.08 (m, 8H), 0.93 (t, $j=7.3 \mathrm{~Hz}, 3 \mathrm{H}), 0.92(\mathrm{~d}, j=7.0 \mathrm{~Hz}, 3 \mathrm{H}), 0.87$ (t, $j=7.2 \mathrm{~Hz}, 3 \mathrm{H}), 0.83(\mathrm{~d}, j=6.9 \mathrm{~Hz}, 3 \mathrm{H}) ;{ }^{13} \mathrm{C} \mathrm{NMR}$ $\left(67.8 \mathrm{MHz}, \mathrm{CDCl}_{3}\right) \delta(\mathrm{ppm}): 11.7,14.0,14.2,14.4,22.8,26.3,28.3$ (x 3), 29.3, 32.2, 36.0, 36.1, 37.6, 56.9, 74.2, 79.8, 155.8, 172.1, 175.4 .

\section{Loading of building Fmoc-Ala-OH onto 2-chlorotrityl chloride resin}

2-Chlorotrityl chloride resin (180 mg) in six MicroKan reactors (30 mg / a reactor) was suspended in $\mathrm{CH}_{2} \mathrm{Cl}_{2}$ and agitated to swell for 15 min followed by filtration. To a suspension of Fmoc-Ala-OH (249 $\mathrm{mg}, 0.80 \mathrm{mmol})$ and the resin in $\mathrm{CH}_{2} \mathrm{Cl}_{2}(8 \mathrm{~mL})$ was added $N, N$-diisopropylethylamine $(0.35 \mathrm{~mL}$, 
$2.0 \mathrm{mmol}$ ). The mixture was agitated at room temperature for $1 \mathrm{~h}$. After removal of reactants by filtration, the resin in MicroKan reactors was washed with DMF (3 $\min x$ 3), $\mathrm{CH}_{2} \mathrm{Cl}_{2}$-methanol (3 min x 1), and $\mathrm{CH}_{2} \mathrm{Cl}_{2}$ (3 min x 3) and dried in vacuo to give 19.

\section{General Procedure for Removal of the Fmoc group}

After swelling of the resin in DMF for 15 min, the resin was suspended in 20\% piperidine in DMF and agitated for $1 \mathrm{~h}$. After filtration, the resulting resin was washed with DMF (3 min x 3) and $\mathrm{CH}_{2} \mathrm{Cl}_{2}$ (3 min x 3) and dried in vacuo.

\section{Couplig of building Fmoc-Phe-OH with polymer supported alanine}

To a suspension of Fmoc-Phe-OH (194 mg, $0.5 \mathrm{mmol})$, HOBt (81.2 mg, $0.6 \mathrm{mmol})$ and the resin in four MicroKans supported alanine in $\mathrm{CH}_{2} \mathrm{Cl}_{2}(4 \mathrm{~mL})$ was added DIC (78.3 $\left.\mu \mathrm{L}, 0.5 \mathrm{mmol}\right)$. The mixture was agitated at room temperature for $3.5 \mathrm{~h}$. After filtration, the resin was washed with DMF (3 min x 4) and $\mathrm{CH}_{2} \mathrm{Cl}_{2}$ (3 min $\mathrm{x} 4$ ) and dried in vacuo to give 20.

\section{General Procedure for Couplig of 14-17}

After removal of the Fmoc group in 20, the resin in one MicroKan was swelled in $\mathrm{CH}_{2} \mathrm{Cl}_{2}(2 \mathrm{~mL})$ for $15 \mathrm{~min}$ and filtered. To a suspension of acid 14 (116 mg, $0.3 \mathrm{mmol})$ and the resin in $\mathrm{CH}_{2} \mathrm{Cl}_{2}(2.4$ $\mathrm{mL})$ and DMF (0.6 mL) was added $N, N$-diisopropylethylamine $(0.11 \mathrm{~mL}, 0.6 \mathrm{mmol})$ and PyBroP (140 $\mathrm{mg}, 0.3 \mathrm{mmol}$ ). The mixture was agitated at room temperature for $1 \mathrm{~h}$. After filtration, the resin was washed with DMF (3 $\min \mathrm{x} 4)$ and $\mathrm{CH}_{2} \mathrm{Cl}_{2}$ (3 $\left.\min \mathrm{x} 4\right)$ and dried in vacuo to give $21 \mathrm{a}$.

\section{Deprotection of the Boc group and cleavage of linear depscipeptide 22 from the polymer}

\section{support}

The resins 21a-d in MicroKans were respectively treated with 4M HCl in dioxane (4 mL) at room temperature for $1 \mathrm{~h}$. After filtration, the resin was washed with $\mathrm{CH}_{2} \mathrm{Cl}_{2}$ (3 min $\mathrm{x}$ 3). The collected filtrate was concetrated in vacuo to give the cyclization precursors 22a-d, in parallel. 


\section{Cyclization of linear depsipeptide 22}

Linear depsipeptide 22a-d (ca. $37.5 \mu \mathrm{mol}$ ) were respectively treated with a cocktail of $\mathrm{N}$ diisopropylethylamine (20 $\mu \mathrm{l}, 0.11 \mathrm{mmol})$ and EDCI (10 mg, $56 \mu \mathrm{mol})$ in $\mathrm{CH}_{2} \mathrm{Cl}_{2}(25 \mathrm{~mL})$. After being stirred at room temperature for $2 \mathrm{~h}$, the mixture was quenched with methanol and was concetrated in vacuo. The crude residue was purified by preparative HPLC to provide the four beauveriolide III isomers 23a(11\%), 23b(10\%), 23c(17\%), and 23d(12\%), respectively.

TABLE S1. Comparison optical rotation of 5, 10, ent-5 and ent-10.

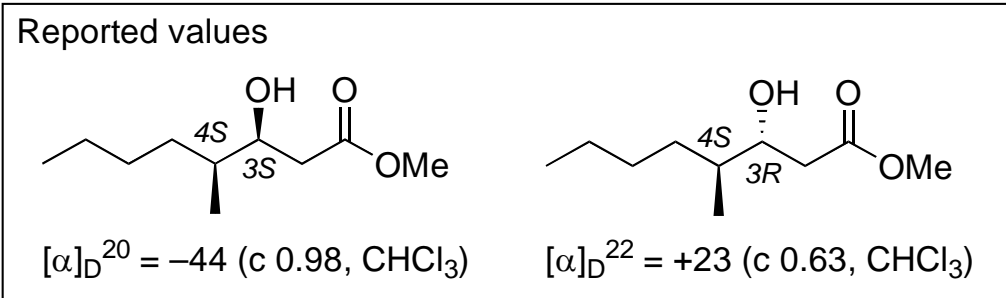




\begin{tabular}{lc}
\hline Compounds & Observed values \\
\hline$(3 S, 4 S) \mathbf{5}$ & {$[\alpha]_{\mathrm{D}}^{28}=-38\left(\right.$ c $\left.0.98, \mathrm{CHCl}_{3}\right)$} \\
$(3 R, 4 S) \mathbf{1 0}$ & {$[\alpha]_{\mathrm{D}}^{29}=+18\left(\right.$ c $\left.1.02, \mathrm{CHCl}_{3}\right)$} \\
$(3 S, 4 R)$ ent-10 & {$[\alpha]_{\mathrm{D}}^{27}=-17\left(\right.$ c $\left.1.02, \mathrm{CHCl}_{3}\right)$} \\
$(3 R, 4 R)$ ent-5 & {$[\alpha]_{\mathrm{D}}{ }^{29}=+39\left(\right.$ c $\left.0.93, \mathrm{CHCl}_{3}\right)$} \\
\hline
\end{tabular}



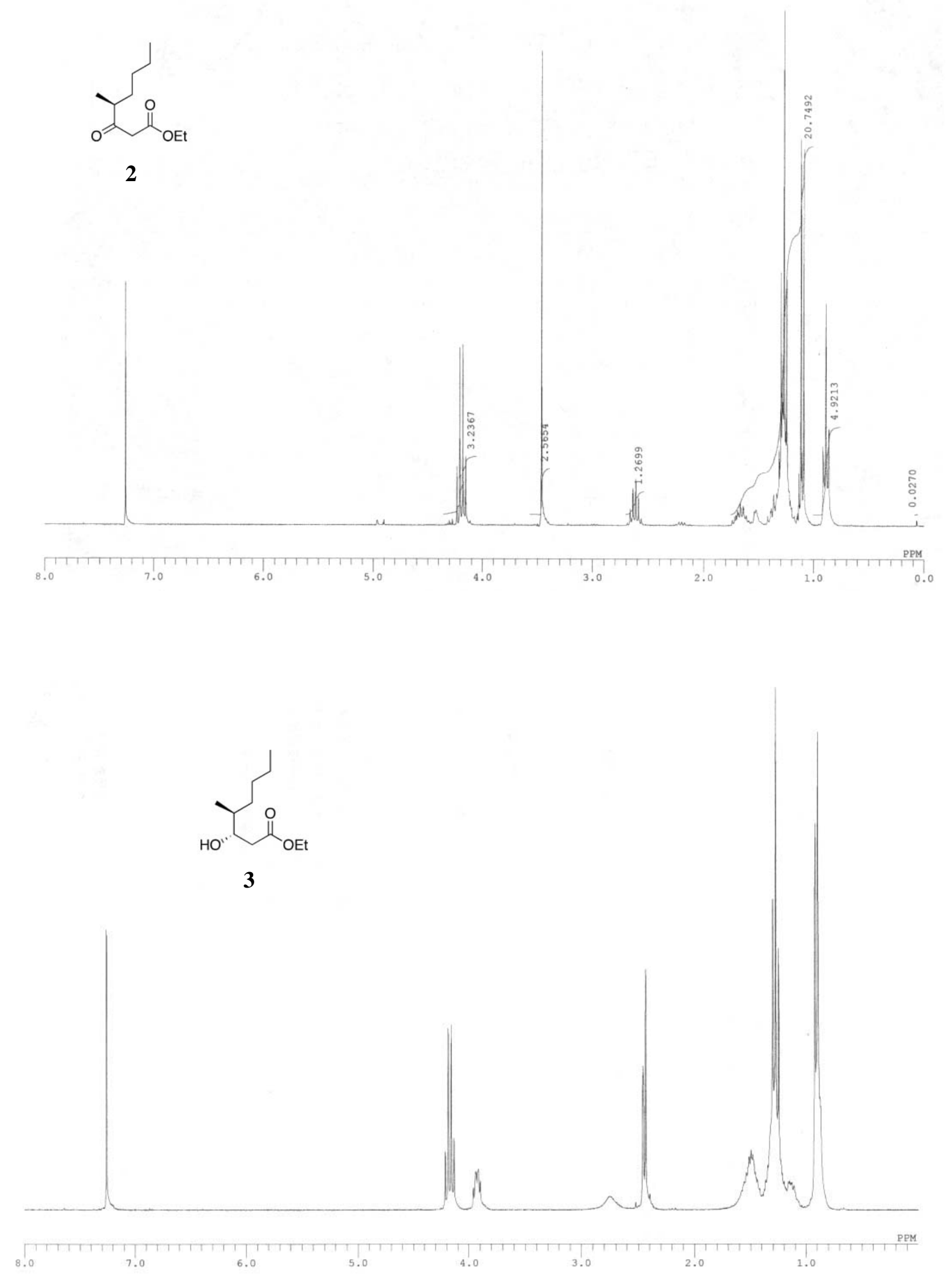

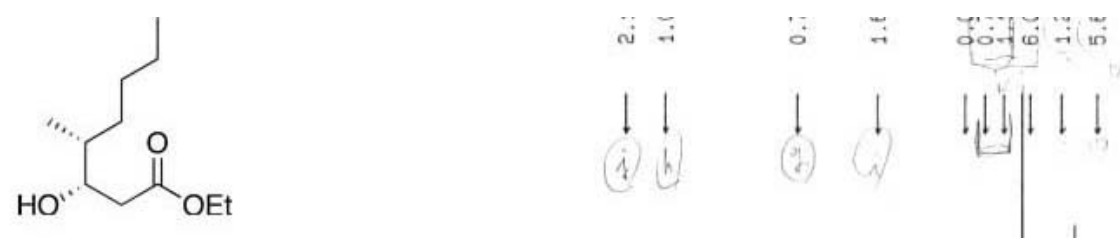

Ethyl (3S, 4R)-3-hydroxy-4-methyloctanoate
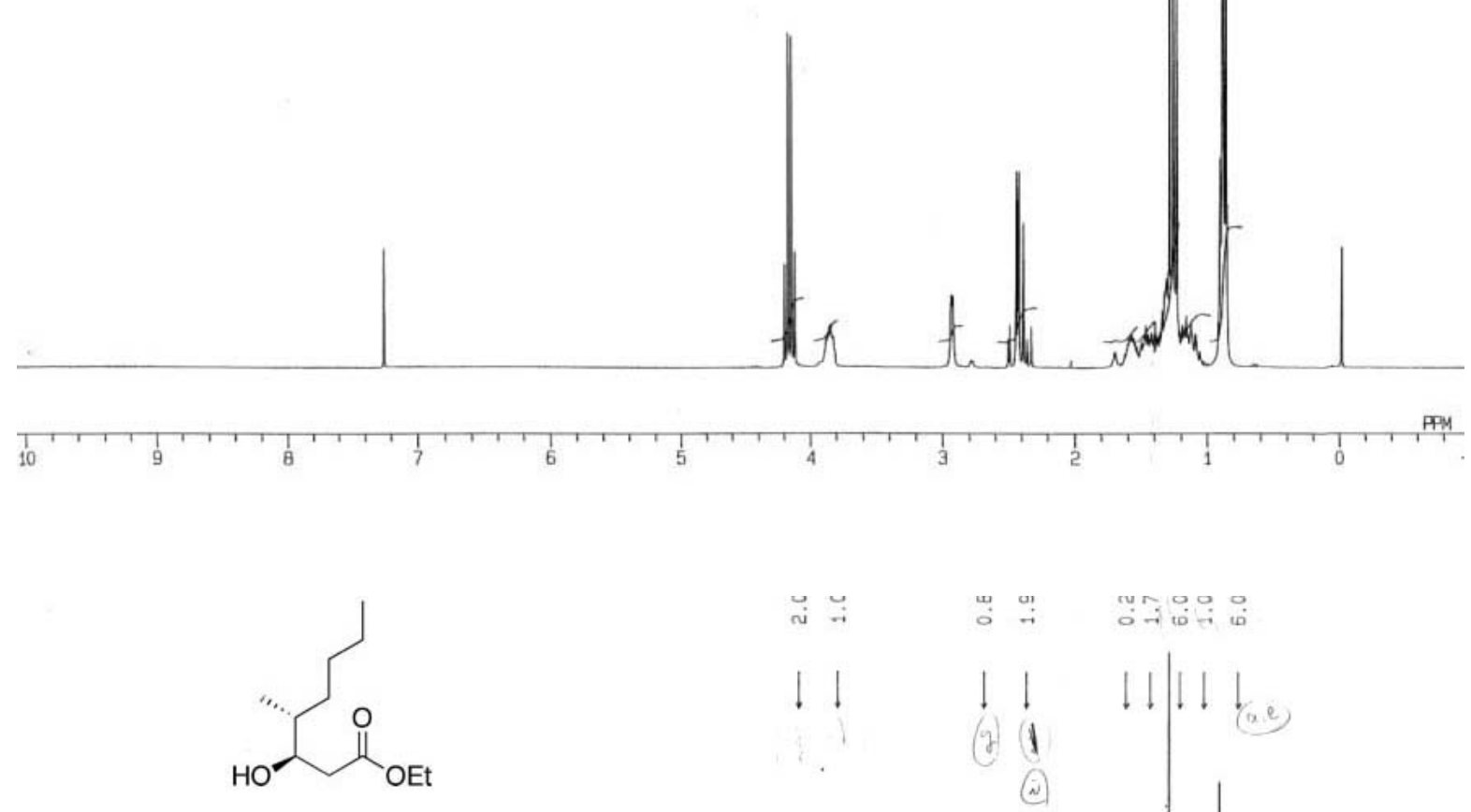

Ethyl (3R, 4R)-3-hydroxy-4-methyloctanoate
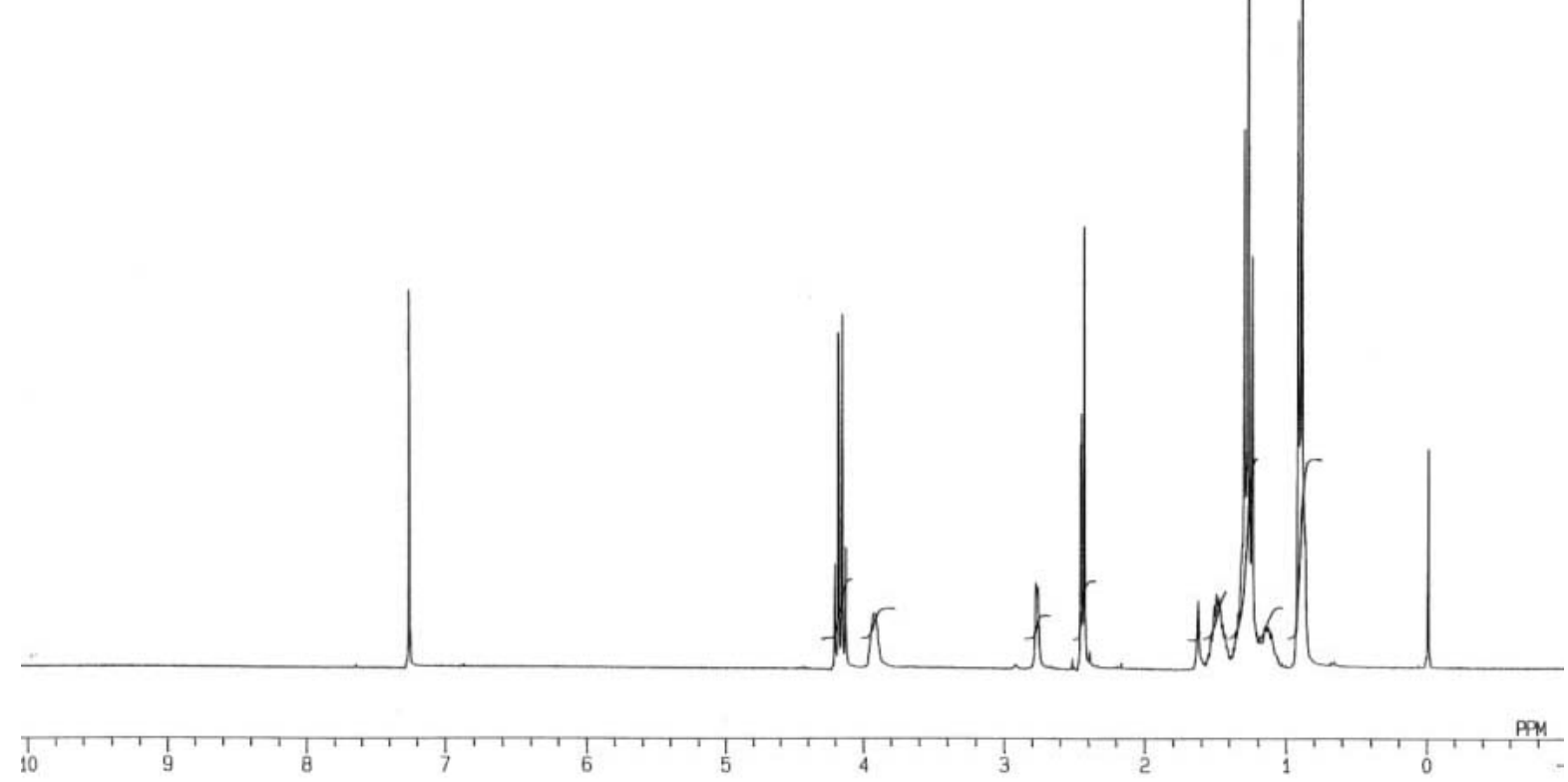


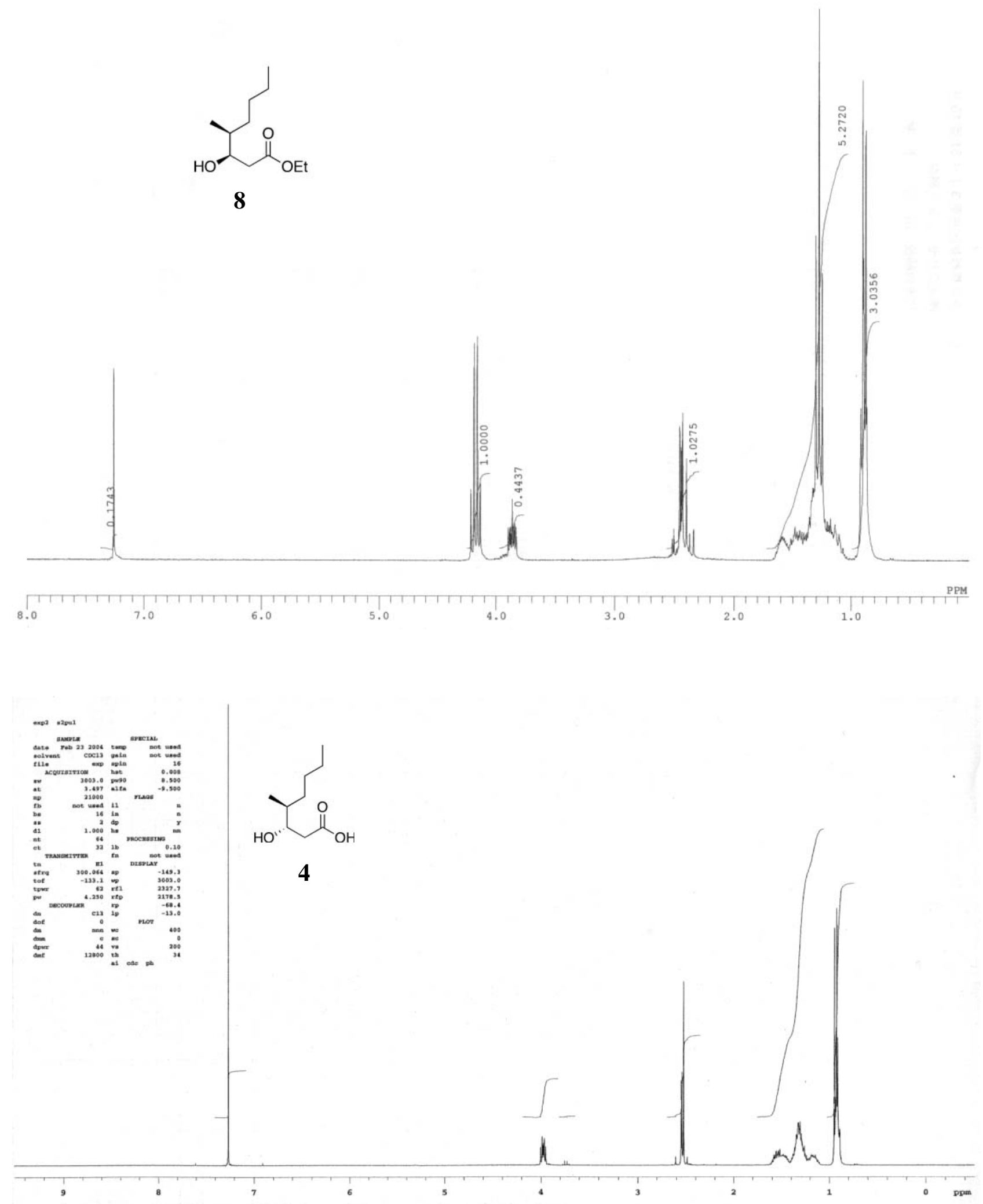



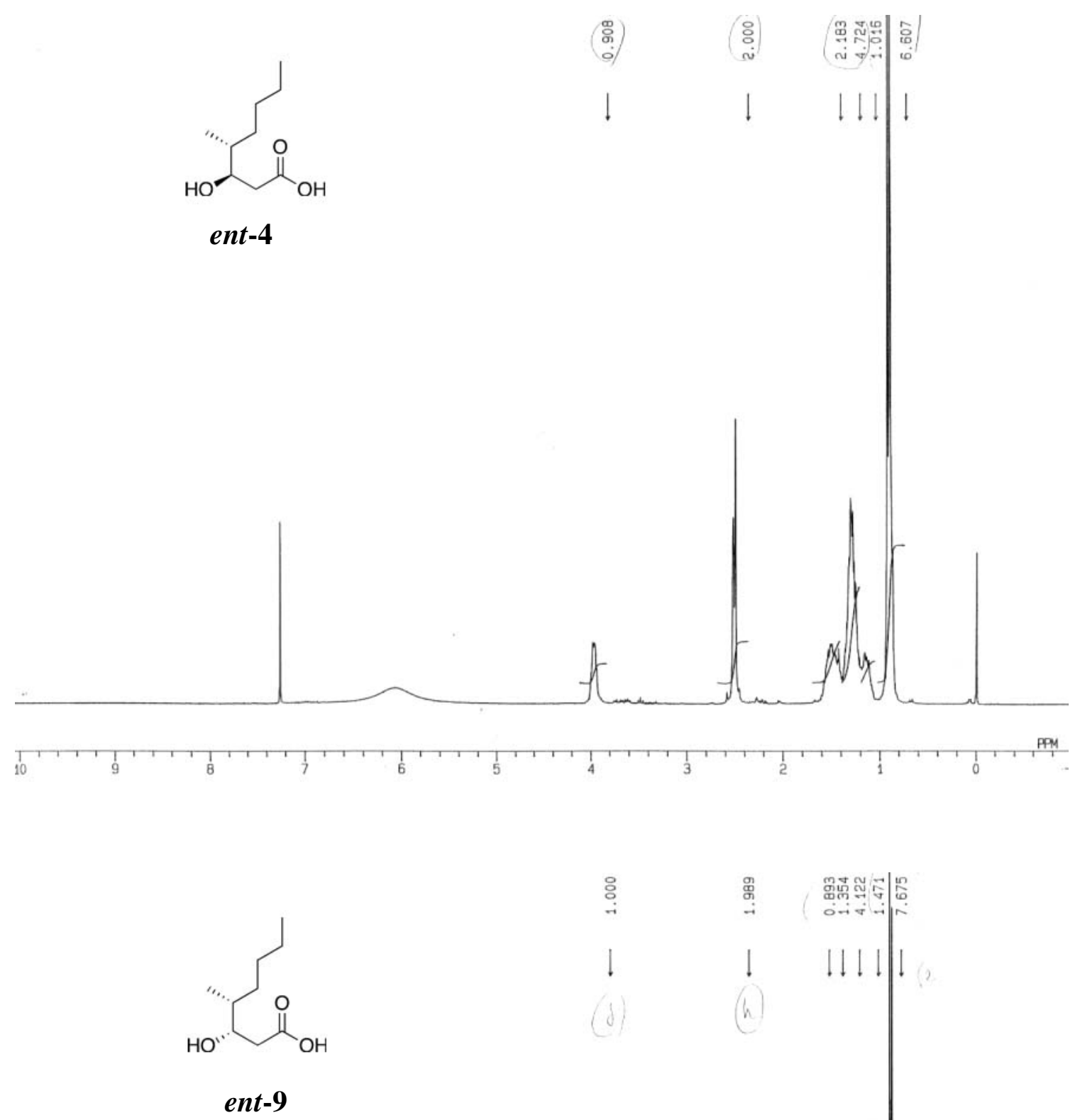

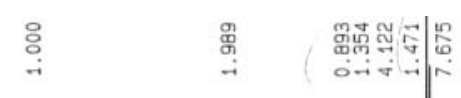
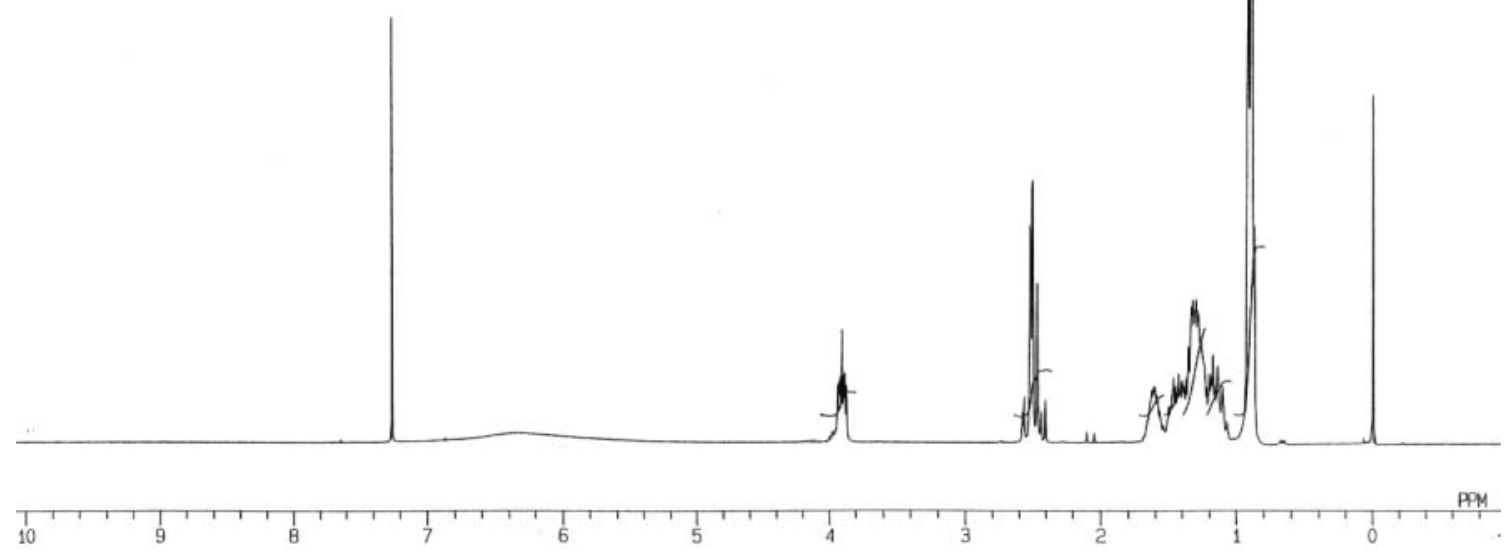


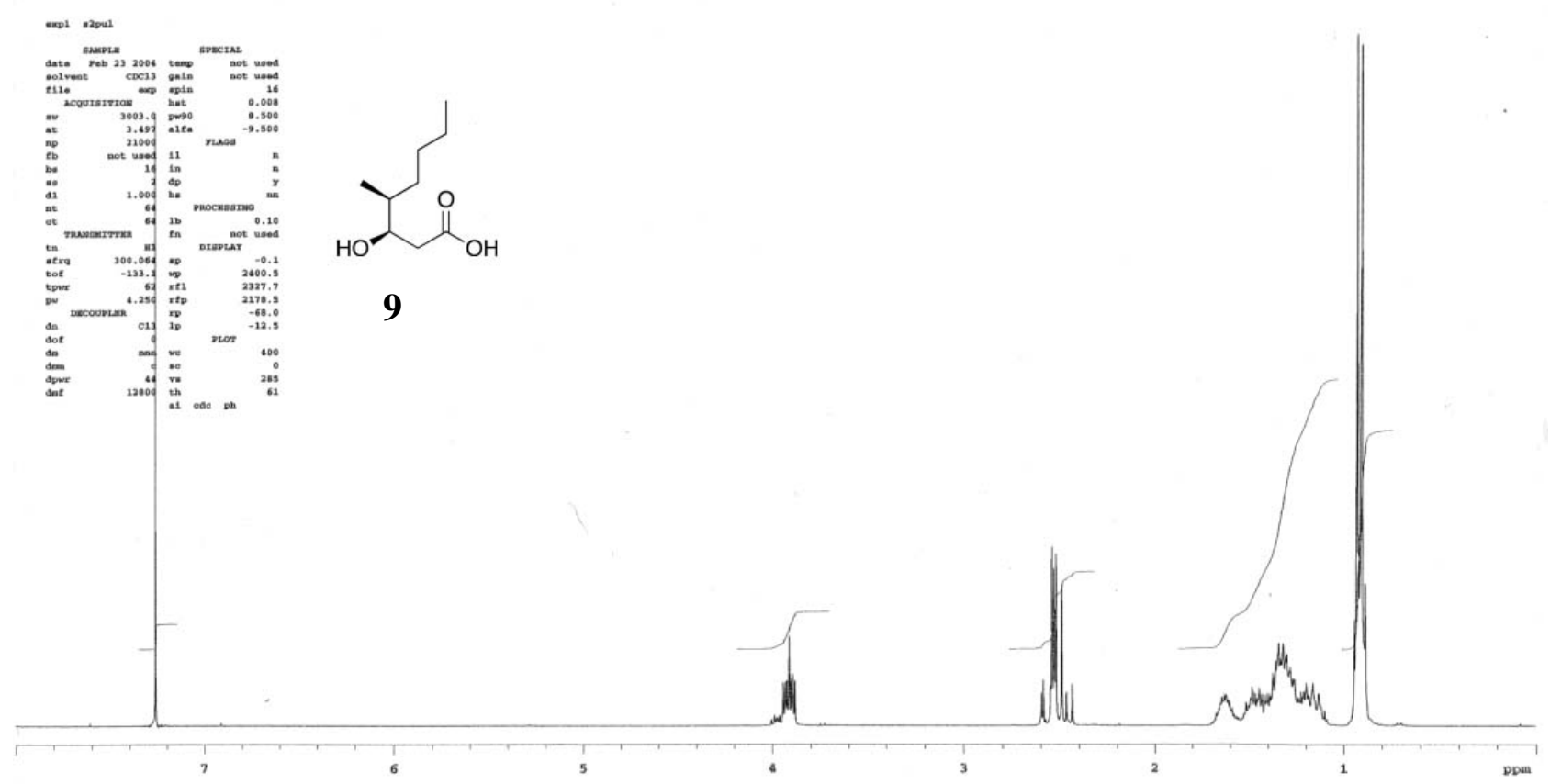

C: \My Documents $\backslash$ nagai $\backslash$ be $3 \backslash$ ot $15 . g x d ; 1$ $05,05,05$
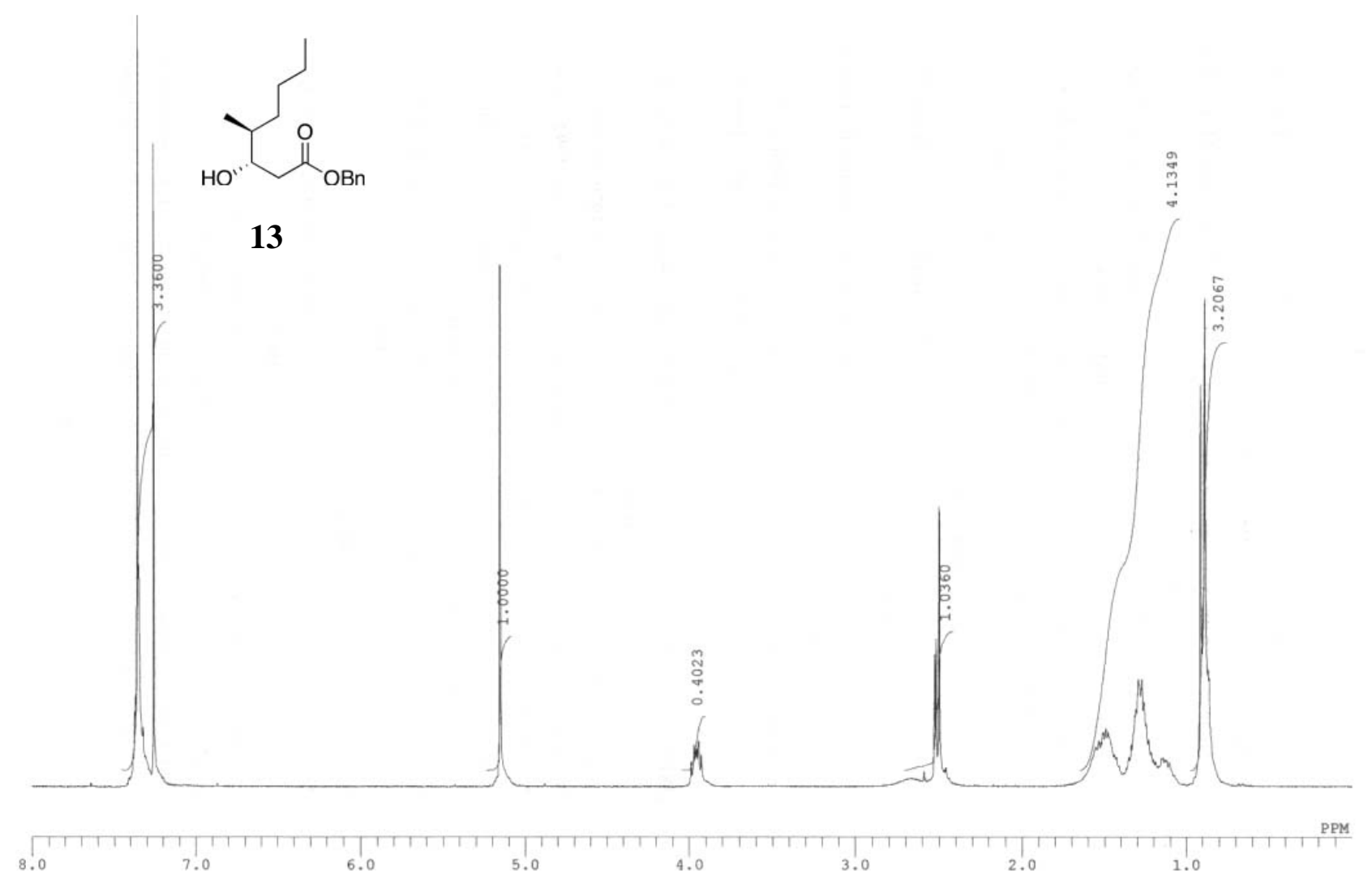


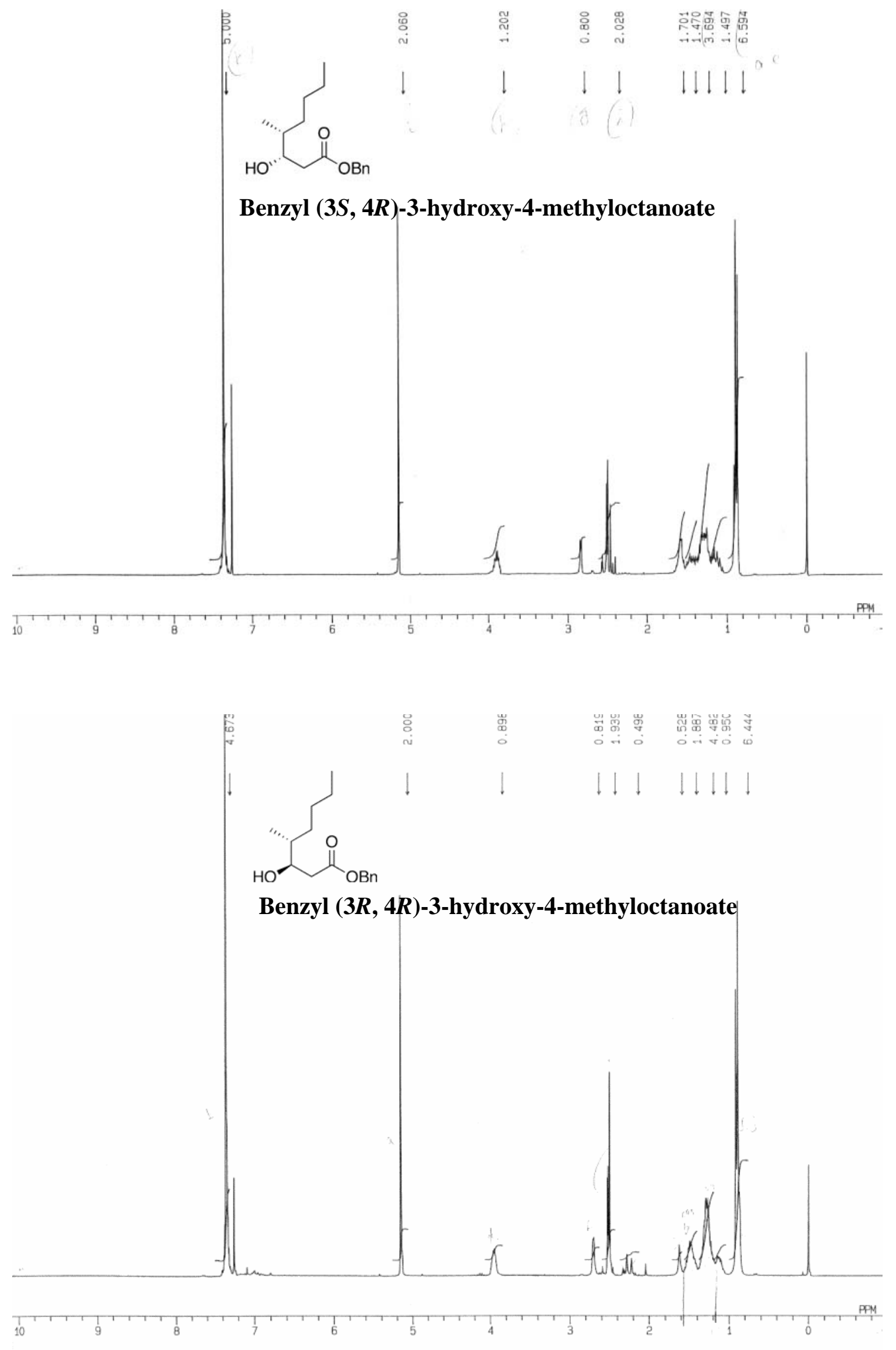




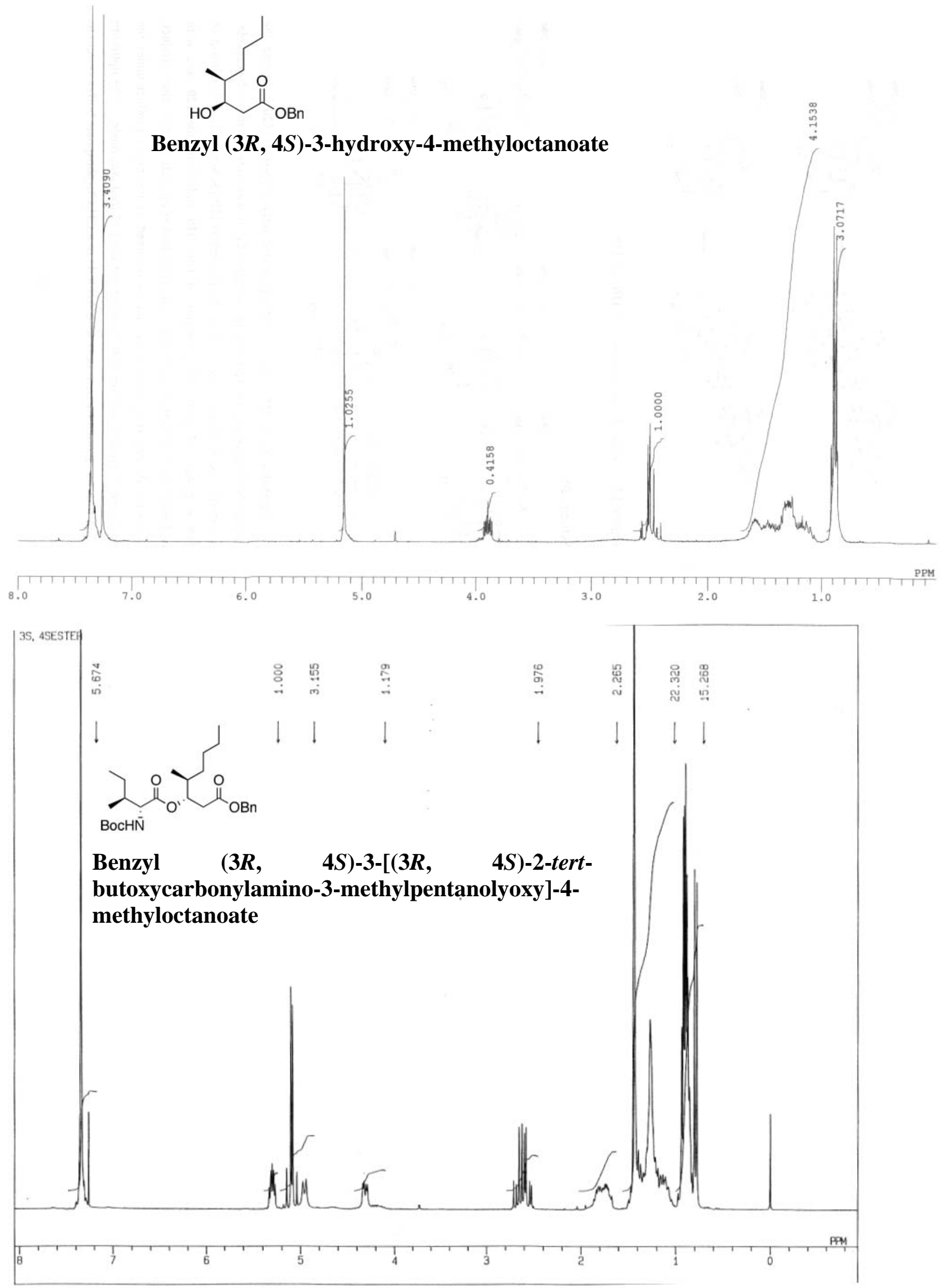



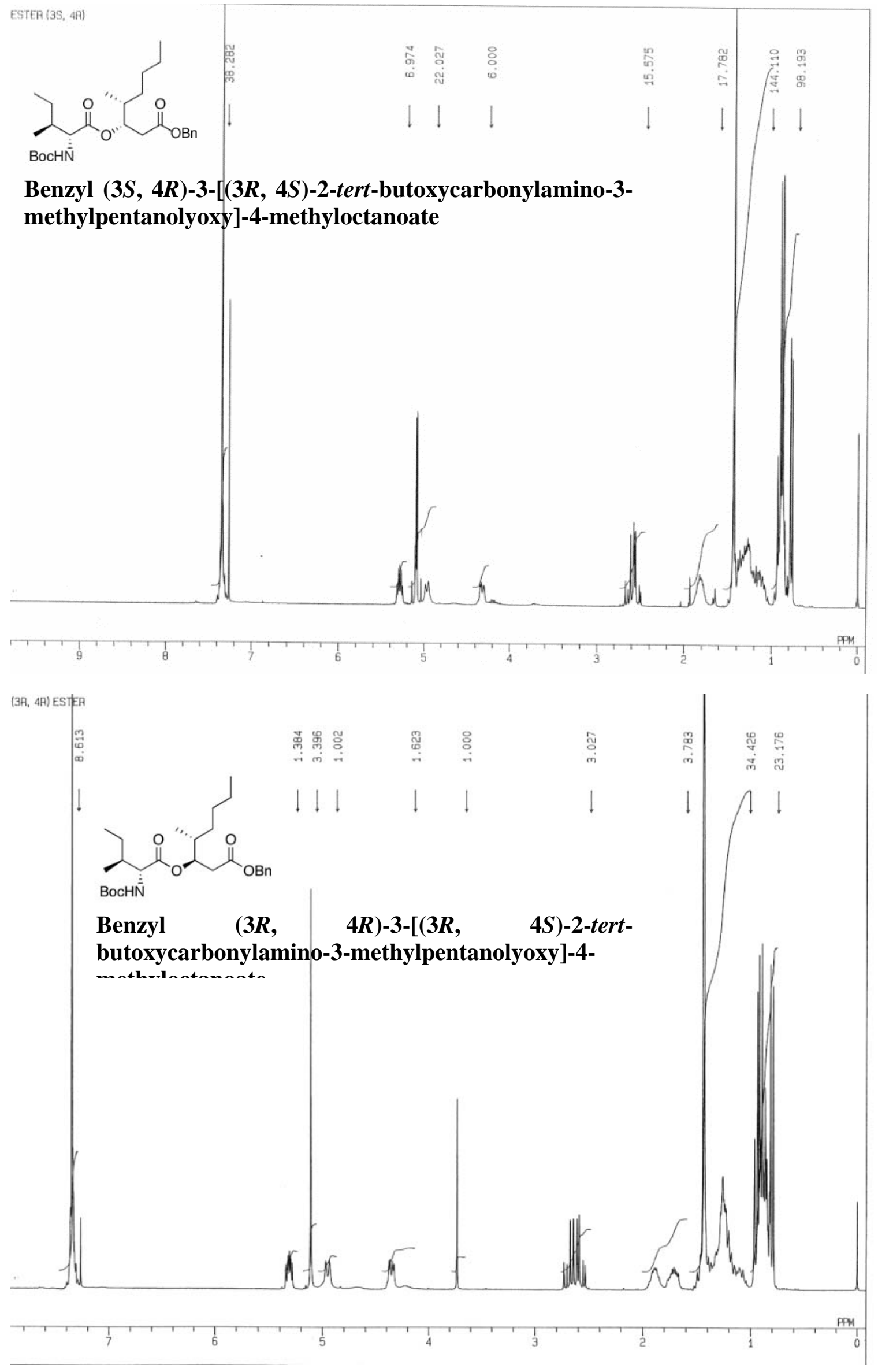


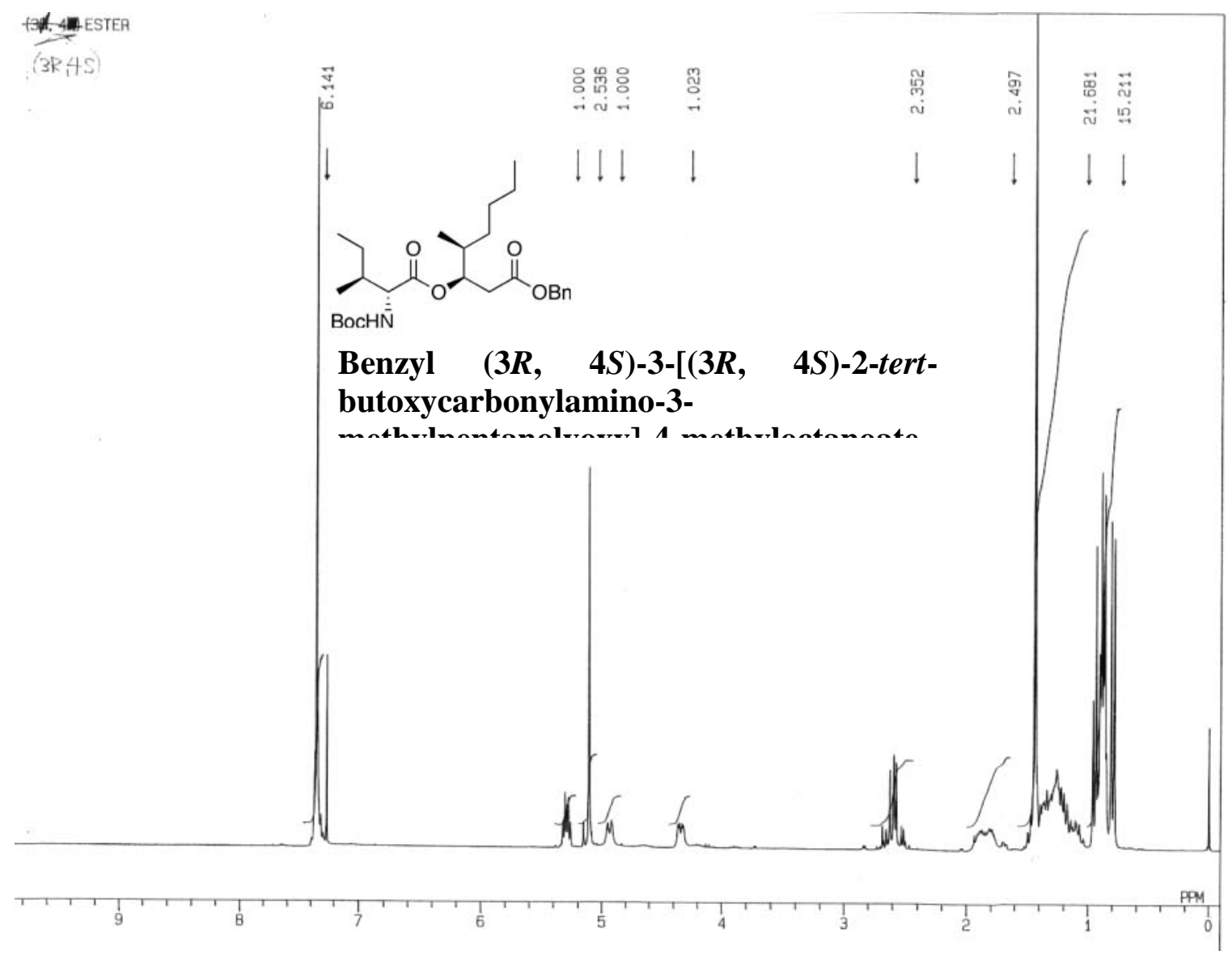

C: \My Documents \nagai $\backslash$ be $3 \backslash$ ot23.gxd; 1
0428

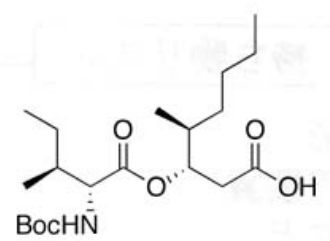

14

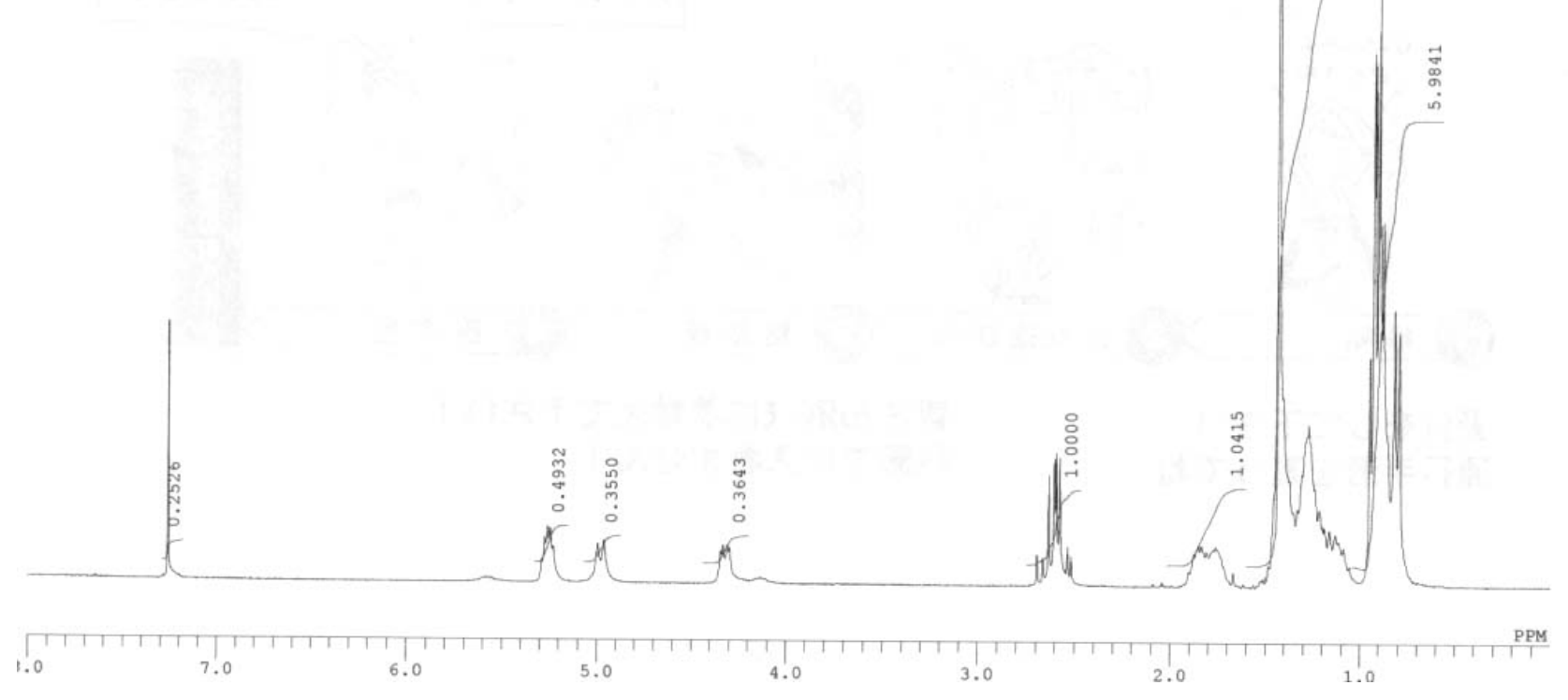



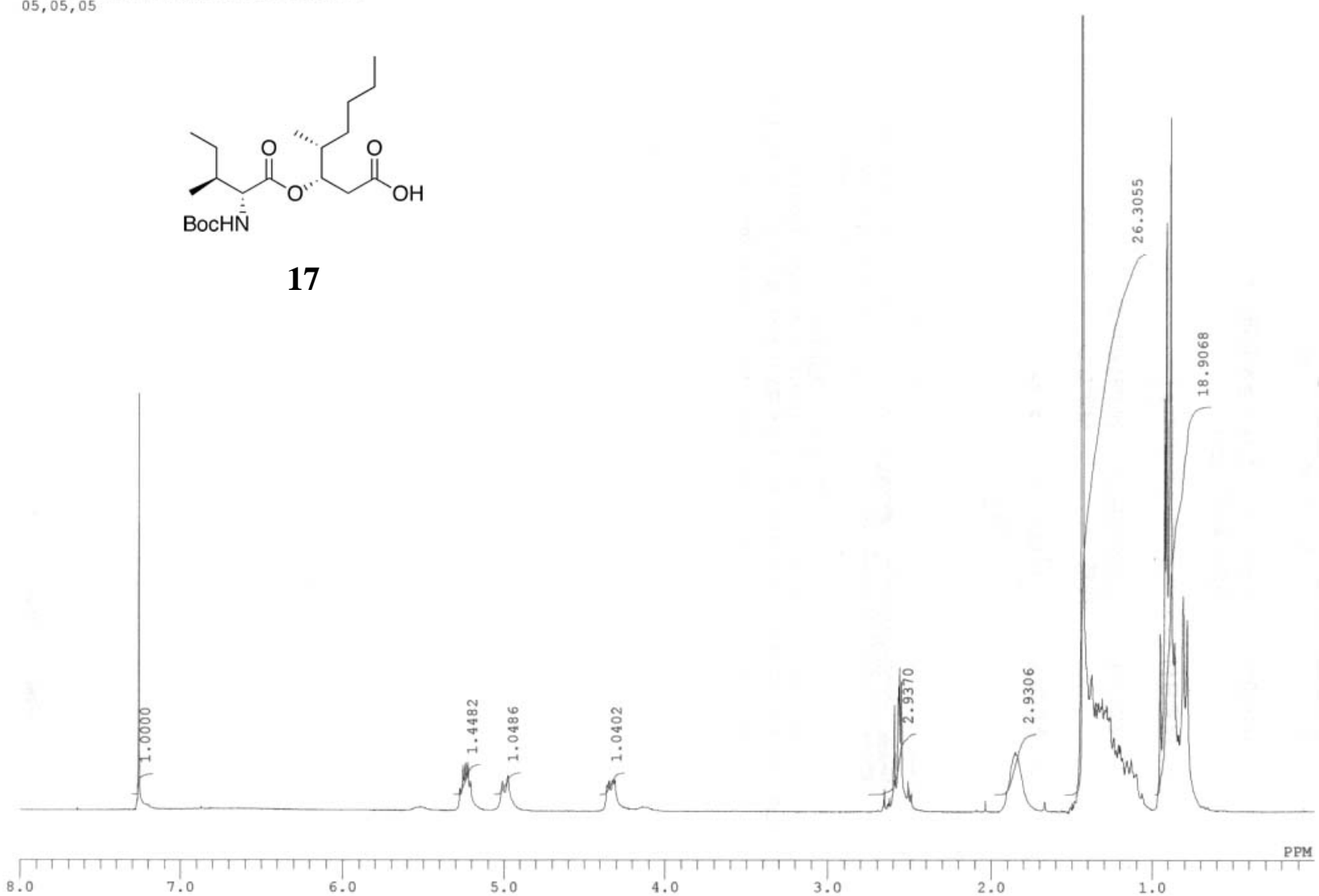

C: \My Documents \nagai \be $3 \backslash$ ot $25 . g x d ; 1$ $05,05,06$

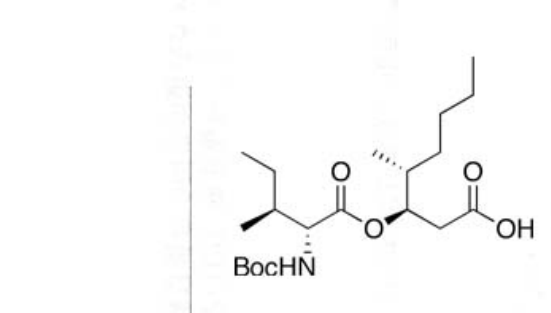

15
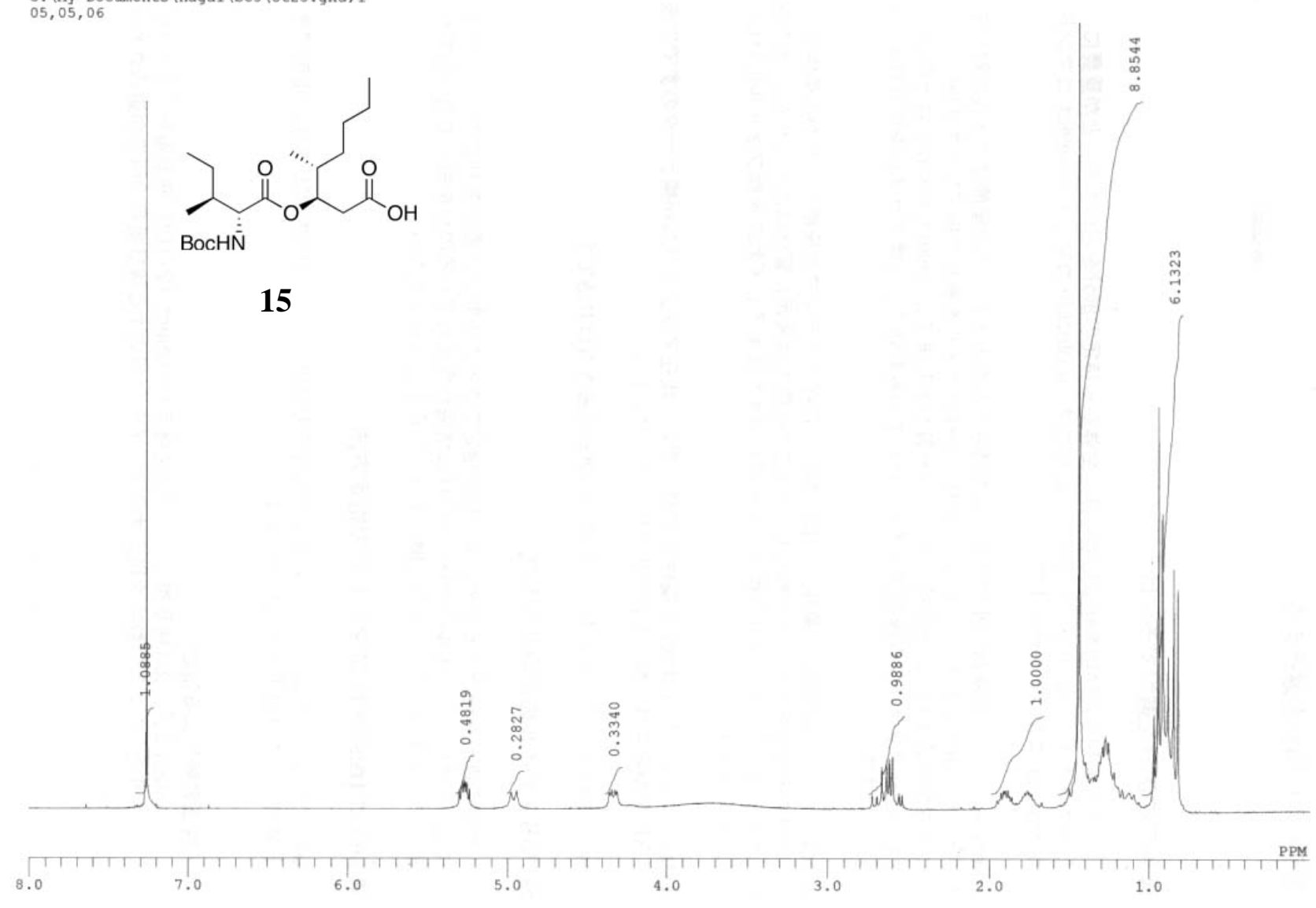


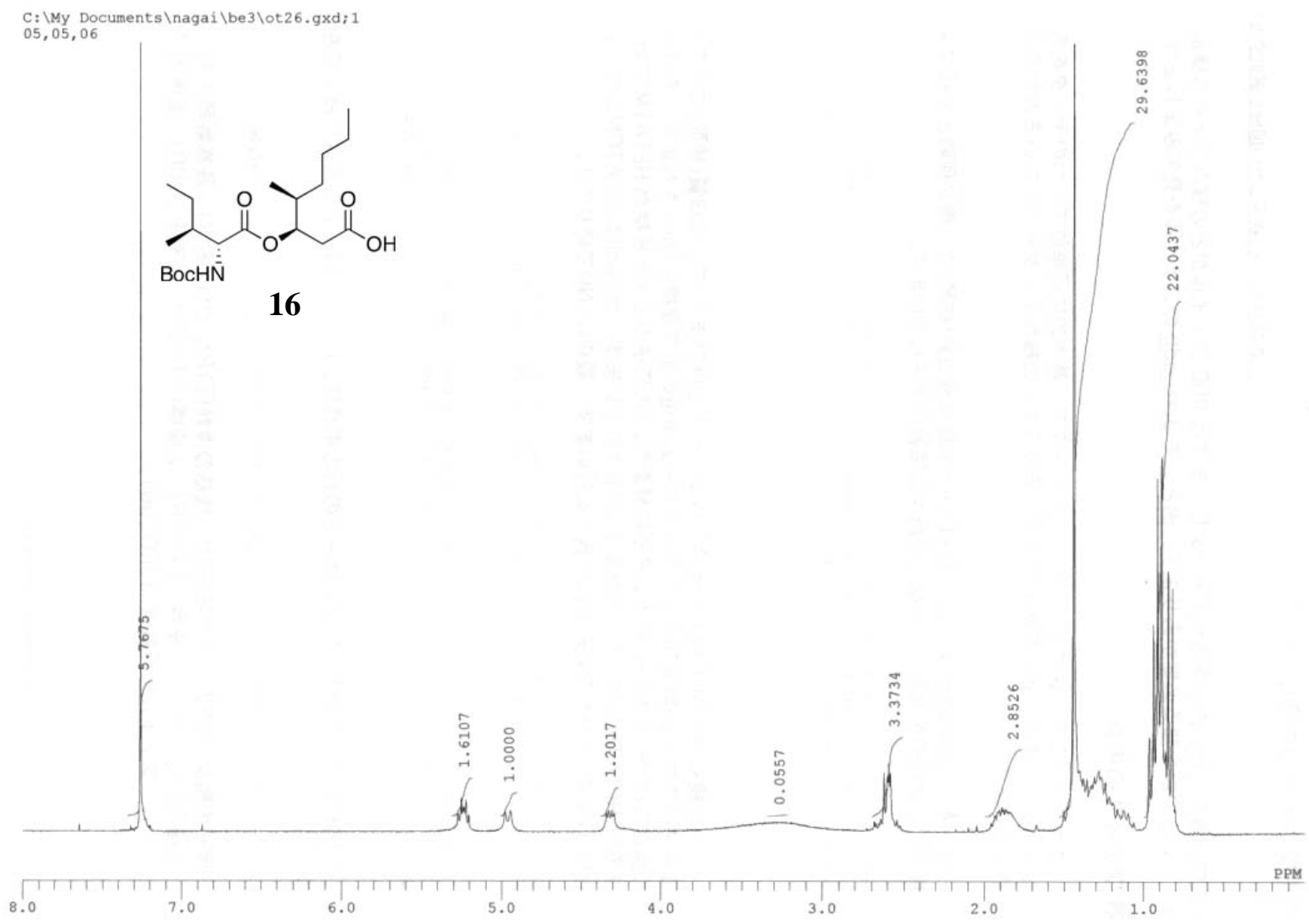


Assay for $\left[{ }^{14} \mathrm{C}\right]$ Neutral Lipid Synthesis by Mouse Peritoneal Macrophages. Macrophages $\left(5\right.$ x $10^{5}$ cells/0.25 mL DMEM containing 7\% (vol/vol) lipoprotein-deficient serum, penicillin (100 units/mL), and streptomycin $(100 \mu \mathrm{g} / \mathrm{mL}))$ were cultured in a 48-well plastic microplate, and then $2.5 \mu \mathrm{L}$ of a sample (methanol solution) and $10 \mu \mathrm{L}$ of liposomes together with $5 \mu \mathrm{L}$ of $\left[{ }^{14} \mathrm{C}\right]$ oleic acid (1 nmol, 1.85 $\mathrm{KBq}, 10 \%$ ethanol/PBS solution) were added to each culture at $37^{\circ} \mathrm{C}$ in $5 \% \mathrm{CO}_{2}$. Following a 14 -h incubation, the medium was removed, and the cells in each well were washed two times with PBS. The cells were lysed by adding $0.25 \mathrm{ml}$ of $10 \mathrm{mM}$ Tris- $\mathrm{HCl}(\mathrm{pH} 7.5)$ containing $0.1 \%(\mathrm{w} / \mathrm{v})$ sodium dodecyl sulfate, and the cellular lipids were extracted by the method of Bligh and Dyer. The organic solvent was reduced by centrifugation under vacuum, and the total lipids were separated on a thin layer chromatography (TLC) plate (silica gel F254) and analyzed with a bioimaging analyzer (BAS 2000) as described previously.

Cellular Neutral Lipid Staining. Macrophages were cultured in a tissue culture chamber with liposomes and inhibitors as described above at $37^{\circ} \mathrm{C}$ in $5 \% \mathrm{CO}_{2}$. After a 14-h incubation, the cells were washed three times with PBS and fixed by soaking in $10 \%$ formalin. Nuclei and intracellular neutral lipid droplets were then stained with hematoxylin and oil red O, respectively, and the stained cells were examined by light microscopy. 